CONTRERAS, Lautaro, "La autorización administrativa como pauta para determinar la conducta típica en los delitos culposos de homicidio y lesiones: una cuestión de orden primario de comportamiento ejemplificada a través del otorgamiento de registros sanitarios".

Polít. Crim. Vol. 14, No 28 (Diciembre 2019), Art. 11, pp. 411-440.

[http://politcrim.com/wp-content/uploads/2019/12/Vol14N28A11.pdf]

\title{
La autorización administrativa como pauta para determinar la conducta típica en los delitos culposos de homicidio y lesiones: una cuestión de orden primario de comportamiento ejemplificada a través del otorgamiento de registros sanitarios ${ }^{*}$
}

\author{
The administrative authorization as a guideline to determine the criminal behavior in \\ the crimes of negligent homicide and injuries: a matter of primary order of conduct \\ exemplified through the grant of marketing authorization \\ Lautaro Contreras Chaimovich \\ Legum magister y doctor por la Albert-Ludwigs-Universität (Alemania) \\ Profesor asociado del Departamento de Ciencias Penales, Universidad de Chile \\ lcontreras@derecho.uchile.cl
}

\begin{abstract}
Resumen
El presente artículo analiza la función que desempeñan las autorizaciones para distribuir productos farmacéuticos en la delimitación entre riesgos tolerados y desaprobados para la vida o salud. Luego de una toma de posición sobre la incardinación sistemático-dogmática y los efectos de tales autorizaciones en el injusto de los delitos imprudentes de homicidio y lesiones, se explica cuáles son los específicos riesgos para la vida y salud que deben estimarse como permitidos con el otorgamiento de las autorizaciones referidas. A continuación, se analizan críticamente las opiniones según las cuales las autorizaciones administrativas no permitirían excluir la responsabilidad penal por la lesión a bienes jurídicos individuales. Posteriormente, se abordan las consecuencias que tienen para el injusto de conducta de los delitos culposos de homicidio y lesiones las autorizaciones para distribuir productos farmacéuticos de carácter inválido pero eficaz. Finalmente, se explica el tratamiento que debe darse a las autorizaciones para distribuir medicamentos que quedan obsoletas con el paso del tiempo.
\end{abstract}

Palabras clave: teoría de la imputación objetiva, delitos culposos, autorizaciones administrativas, registros sanitarios, accesoriedad del Derecho penal

\begin{abstract}
The article analyzes the function of the authorization to distribute pharmaceutical products in the delimitation between tolerated and disapproved risks for life or health. Following a position regarding the systemic-dogmatic incardination and the effects that such authorizations have over the wrongdoing in the crimes of negligent homicide and injuries, the article explains which are the specific risks to life and health that must be estimated as permitted with the grant of the aforementioned authorizations. Then, it critically analyses the opinions according to which the administrative authorizations do not exclude criminal responsibility for the harm to individual legally protected rights. Subsequently, it addresses the consequences that authorizations to distribute pharmaceutical products characterized as invalid but effective have over crimes of negligent homicide and injuries. Finally, it explains the treatment that must be given to authorizations to distribute medications that become obsolete with the passing of time.
\end{abstract}

Keywords: objective imputation theory, criminal negligence, administrative authorizations, marketing authorization, accessory nature of criminal law.

\footnotetext{
* Este trabajo ha sido desarrollado en el marco del proyecto Fondecyt de Iniciación No 11160021, "La determinación del deber de cuidado en los delitos culposos de resultado". Agradezco a Luis Emilio Rojas y a Jorge Cabrera por sus valiosas observaciones a la versión preliminar del presente trabajo.
} 
CONTRERAS, Lautaro, "La autorización administrativa como pauta para determinar la conducta típica en los delitos culposos de homicidio y lesiones: una cuestión de orden primario de comportamiento ejemplificada a través del otorgamiento de registros sanitarios".

\section{Introducción}

La delimitación entre peligros permitidos y desaprobados tratándose de los delitos culposos de homicidio y lesiones representa un problema esencial, y de difícil solución, en la determinación del injusto de comportamiento de estos ilícitos. Efectivamente, en la mayoría de los casos de muertes y daños a la salud atribuibles a imprudencia, los riesgos creados por el autor son menos intensos en comparación con los supuestos donde existe dolo. Además, tales riesgos tienen su origen en conductas que habitualmente traen aparejada una importante utilidad social. ${ }^{1}$

Para facilitar la delimitación entre peligros permitidos y desaprobados, la dogmática ha estudiado detalladamente distintos criterios o pautas de solución, tales como el principio de confianza, la relación utilidad-peligro de la conducta, los programas estatales de reducción o eliminación de riesgos, las regulaciones extrajurídicas, o el modelo de la figura-baremo. ${ }^{2}$ Por el contrario, el rol que pueden cumplir las autorizaciones administrativas, en la definición del injusto de comportamiento de los delitos culposos de homicidio y lesiones, no ha sido objeto de un estudio pormenorizado por parte de la doctrina. ${ }^{3}$ ¿Qué debemos entender por autorizaciones administrativas en el contexto de este trabajo? Se trata de decisiones formales que emiten órganos de la Administración del Estado, en el ejercicio de una potestad pública; ${ }^{4}$ por su intermedio, se aprueba la realización de determinadas actividades riesgosas como, por ejemplo, el funcionamiento de clínicas y hospitales, de pabellones de cirugía menor, de equipos de radiación ionizante, de mataderos y frigoríficos; la fabricación de plaguicidas o subproductos de aguas minerales, etc. ${ }^{5}$ Como se puede apreciar, los ámbitos donde la Administración está facultada para autorizar actividades, que pueden conllevar peligros relevantes para bienes jurídicos básicos, son múltiples.

La ausencia de interés por parte de la dogmática de los delitos culposos en las autorizaciones administrativas impide dar una respuesta satisfactoria a una serie de cuestiones relevantes vinculadas con estos actos, concretamente: ¿es posible que un permiso estatal para realizar una actividad excluya la responsabilidad penal, tratándose de

\footnotetext{
${ }^{1}$ Así MURMANN, Uwe, Grundkurs Strafrecht, 4a edición, München: C.H. Beck, 2017, § 23 número marginal 36.

${ }^{2}$ Una completa visión panorámica sobre estos criterios o pautas de solución se encuentra en VOGEL, Joachim, “§ 15 Vorsätzliches und fahrlässiges Handeln”, en: LAUFHÜTTE, Heinrich et al (Editores), Strafgesetzbuch Leipziger Kommentar Großkommentar, 12a edición, Berlin: Walter de Gruyter, 2007, números marginales 216 y ss.; en el Derecho chileno véase BUSTOS, Juan, El delito culposo, Santiago: Editorial Jurídica de Chile, 1995, pp. 38 y ss., 46 y ss.

${ }^{3} \mathrm{Si}$ bien pueden encontrarse algunas reflexiones sobre el papel de las autorizaciones administrativas en MIKUS, Rudolf, Die Verhaltensnorm des fahrlässigen Erfolgsdelikts, Berlin: Duncker \& Humblot, 2002, pp. 85 y ss., estas se circunscriben únicamente a los delitos imprudentes ambientales. Por su parte, SternbergLieben solo desarrolla la siguiente consideración general sobre el problema: "De forma análoga a lo que ocurre con las normas técnicas o las tomas de posición de la autoridad, la autorización [administrativa] otorgada debe considerarse como una concretización del riesgo permitido, que excluye una lesión al deber de cuidado (...)"; véase STERNBERG-LIEBEN, Detlev, "Vorbemerkungen zu den $\S \S 32$ ff.", en: Schönke/Schröder Strafgesetzbuch Kommentar, 30ª edición, München: C.H. Beck, 2018, número marginal 63d, en: https://beck-online.beck.de [visitado el 23.01.2019]. Entre nosotros, se ha investigado el efecto en el injusto penal de actos emanados de particulares en el ejercicio de funciones públicas (revisiones técnicas realizadas a vehículos motorizados), así MAYER, Laura; VERA, Jaime, "Autorización de plantas de revisión técnica e imputación objetiva en delitos culposos del tráfico vehicular", Revista de Derecho (Valdivia), vol. XXXI, No 1 (2018), pp. 327-345, pp. 327 y ss., pero siguen sin examinarse las consecuencias en el injusto penal de las autorizaciones administrativas. Por otra parte, el papel que desempeñan estas autorizaciones en el injusto no es un asunto baladí, como lo demuestra la regulación prevista en el art. 46 del Proyecto de ley que establece un nuevo Código Penal (Boletín 9.274-07), y en el art. 42 del reciente Anteproyecto de Código Penal.

${ }^{4}$ Cfr. art. $3^{\circ}$, inc. $2^{\circ}$, de la Ley $\mathrm{N}^{\mathrm{o}} 19.880$, que establece las bases de los procedimientos administrativos que rigen los actos de los órganos de la Administración del Estado.

${ }^{5}$ Véase el Decreto con Fuerza de Ley N ${ }^{\circ} 1$ de 1989 del Ministerio de Salud, que fija las materias que requieren autorización sanitaria expresa, publicado en el Diario Oficial el 21.02.1990.
} 
la lesión a bienes jurídicos individuales como la vida y la salud? ¿Cuál es la incardinación sistemático-dogmática y los efectos del permiso estatal en el injusto de los delitos imprudentes de homicidio y lesiones: elimina el carácter típico o antijurídico de la conducta? Finalmente: ¿cuál es el efecto que producen en el injusto de los delitos referidos los permisos estatales inválidos, pero eficaces jurídicamente?

Uno de los pocos ámbitos donde se han estudiado las consecuencias de las autorizaciones administrativas en el injusto de los delitos imprudentes de homicidio o lesiones ha sido el de la responsabilidad penal del fabricante. Así, en el contexto de las autorizaciones para comercializar productos farmacéuticos, ${ }^{6}$ se han abordado con cierto detalle los vínculos existentes entre los permisos estatales y la exigencia de creación de un riesgo jurídicamente desaprobado para la vida o la salud. ${ }^{7}$ A través del análisis de este tipo de autorizaciones, previstas también en el Derecho chileno bajo la expresión "otorgamiento de registros sanitarios", el presente artículo pretende responder a las preguntas planteadas en el párrafo anterior.

Las tesis fundamentales que se plantean en este trabajo son dos. Primera: con el otorgamiento de un registro sanitario, la respectiva conducta de distribución de productos farmacéuticos queda comprendida en el ámbito del ejercicio de la libertad de acción del titular del registro; en consecuencia, esa conducta únicamente generará riesgos tolerados respecto de la vida y salud individual, quedando fuera del ámbito típico de los delitos imprudentes de homicidio y lesiones. Segunda: la distribución de un medicamento, autorizada por un registro sanitario que no cumple con todos los requisitos a los que el Derecho subordina su validez, no genera peligros desaprobados, en la medida que el vicio de nulidad no sea evidente para el titular del registro.

El artículo se dividirá en cuatro partes. En la primera, se expondrá brevemente el sistema de autorizaciones que rige la distribución de productos farmacéuticos en el Derecho chileno; esta exposición permitirá bosquejar la regulación extrapenal que rige el otorgamiento de registros sanitarios (a continuación, infra 1). Posteriormente, se explicará cuál es la ubicación que tiene en la estructura del delito la concesión de un registro sanitario, y cuáles son los efectos que este despliega en el injusto de los delitos culposos de homicidio y lesiones (infra 2). A continuación, se abordarán las consecuencias que acarrea en la responsabilidad penal el otorgamiento de registros sanitarios inválidos pero eficaces (infra 3). Luego, se explicará el tratamiento que debe darse a los registros sanitarios que quedan obsoletos con el paso del tiempo (infra 4). Por último, se expondrán las conclusiones.

\footnotetext{
${ }^{6}$ De acuerdo con el art. 95, inc. $1^{\circ}$, del Código Sanitario, un producto farmacéutico es "cualquier substancia natural, biológica, sintética o las mezclas de ellas, originada mediante síntesis o procesos químicos, biológicos o biotecnológicos, que se destine a las personas con fines de prevención, diagnóstico, atenuación, tratamiento o curación de las enfermedades o sus síntomas o de regulación de sus sistemas o estados físiológicos particulares, incluyéndose en este concepto los elementos que acompañan su presentación y que se destinan a su administración".

${ }^{7}$ Véase GROßE VORHOLT, André, Behördliche Stellungnahmen in der strafrechtlichen Produkthaftung Zur Konkretisierung von Sorgfaltspflichten bei Risikoentscheidungen, Baden-Baden: Nomos, 1997, pp. 121 ss., 191 ss.; HORN, Eckhard, "Erlaubtes Risiko und Risikoerlaubnis - Zur Funktion des Prüfstellensystems nach § 155 AE", en: STRATENWERTH, Günter (Editor), Festschrift für Hans Welzel zum 70. Geburtstag am 25. März 1974, Berlin: Walter De Gruyter, 1974, pp. 719-737, pp. 719 y ss.; MAYER, Michael, Strafrechtliche Produktverantwortung bei Arzneimittelschäden - Ein Beitrag zur Abgrenzung der Verantwortungsbereiche im Arzneiwesen aus strafrechtlicher Sicht, Berlin: Springer, 2008, pp. 323 y ss., 547 y ss.; MAYER, Michael, "Die Arzneimittelzulassung als Strafbarkeitshindernis", MedR (2008), pp. 595-598, pp. 595 y ss.; TIEDEMANN, Klaus, "Körperverletzung und strafrechtliche Produktverantwortung Bemerkungen zum Fall Degussa”, en: WEIGEND, Thomas; KÜPPER, Georg (Editores.), Festschrift für Hans Joachim Hirsch zum 70. Geburtstag am 11. April 1999, Berlin: Walter de Gruyter, 1999, pp. 765-778, pp. 775 y ss.; WEI $\beta$, Holger, Die rechtliche Gewährleistung der Produktsicherheit, Baden-Baden: Nomos, 2008, pp. 503 y ss.
} 
CONTRERAS, Lautaro, "La autorización administrativa como pauta para determinar la conducta típica en los delitos culposos de homicidio y lesiones: una cuestión de orden primario de comportamiento ejemplificada a través del otorgamiento de registros sanitarios".

\section{El sistema de otorgamiento de registros sanitarios}

\subsection{El otorgamiento de registros sanitarios como requisito para la distribución de productos farmacéuticos}

Para que un producto farmacéutico pueda ser distribuido en Chile, es indispensable que el Instituto de Salud Pública ${ }^{8}$ otorgue la respectiva autorización, ${ }^{9}$ luego de evaluar y estudiar de manera exhaustiva las propiedades farmacéuticas, farmacológicas, toxicológicas y clínicas del medicamento. ${ }^{10}$ El procedimiento administrativo en el cual se evalúan y estudian esas propiedades, que puede finalizar con el otorgamiento de una autorización para distribuir el producto farmacéutico, está regulado de manera detallada en el "Reglamento del sistema nacional de control de los productos farmacéuticos de uso humano". "De acuerdo con este cuerpo normativo, el procedimiento se inicia con una "solicitud de registro sanitario", que presenta la respectiva empresa, y a la cual se acompaña un conjunto de documentos administrativos, de información técnica, de calidad farmacéutica, y de seguridad y eficacia clínica del producto. ${ }^{12} \mathrm{Si}$, después del análisis detallado de estos documentos, el Instituto comprueba la calidad, seguridad y eficacia del medicamento, se procede a otorgar el respectivo registro sanitario, mediante la dictación de una resolución que autoriza la distribución del producto. ${ }^{13}$ Esta resolución puede imponer obligaciones específicas al titular del registro sanitario (v. gr., que el respectivo folleto informativo describa ciertos riesgos derivados del uso del producto). ${ }^{14}$ El registro del correspondiente producto farmacéutico tiene una vigencia de cinco años y puede ser renovado por períodos iguales y sucesivos. $^{15}$

\subsection{El otorgamiento de registros sanitarios como caso de control represivo con reserva de exención}

La resolución que otorga el registro sanitario de un producto farmacéutico constituye una autorización administrativa. Las autorizaciones administrativas representan actos administrativos de contenido favorable para sus titulares, al restaurar o ampliar sus esferas de libertad de acción. ${ }^{16}$ Estas autorizaciones pueden dictarse en el marco de sistemas de control preventivo con reserva de permiso o bien de control represivo con reserva de

\footnotetext{
${ }^{8}$ En adelante, indistintamente, el "Instituto" o "ISP". El Instituto es un servicio público funcionalmente descentralizado, dotado de personalidad jurídica y patrimonio propio, dependiente del Ministerio de Salud.

${ }^{9}$ Véanse el art. 97, inc. $1^{\circ}$, del Código Sanitario y el art. 20 del Reglamento del sistema nacional de control de los productos farmacéuticos de uso humano.

${ }^{10} \mathrm{Cfr}$. art. 18 , inc. $1^{\mathrm{o}}$, del Reglamento del sistema nacional de control de los productos farmacéuticos de uso humano.

${ }^{11}$ En adelante, el "Reglamento de productos farmacéuticos" o el "Reglamento". Este reglamento fue aprobado mediante Decreto 3/10 del Ministerio de Salud, publicado en el Diario Oficial el 25.06.2011.

${ }^{12}$ Art. 28 del Reglamento.

${ }^{13}$ Cfr. arts. 18 y 47 del Reglamento.

${ }^{14}$ Véase el art. 48 letra $\mathrm{n}$ ) del Reglamento. Estas obligaciones representan cláusulas accesorias del acto administrativo que concede el registro sanitario. Concretamente, estamos frente a lo que la doctrina del Derecho administrativo ha denominado como "modos". Estos constituyen exigencias vinculadas a un acto administrativo favorable, a través de las cuales se impone al interesado una determinada obligación de hacer, de no hacer o de soportar (BOCANEGRA, Raúl, Lecciones sobre el acto administrativo, $4^{\mathrm{a}}$ edición, Cizur Menor: Thomson Reuters, 2012, p. 95; detalladamente VELASCO, Francisco, Las cláusulas accesorias del acto administrativo, Madrid: sin editorial, 1994, pp. 132 y ss., en: https://repositorio.uam.es/xmlui/handle/10486/4881 [visitado el 10.08.2018]; sobre los modos en el Derecho alemán véase KORTE, Stefan, “§ 47 Nebenbestimmungen zu Verwaltungsakten”, en: Wolff/Bachof/Stober/Kluth Verwaltungsrecht, t. I, $13^{\text {a }}$ edición, München: C.H. Beck, 2017, números marginales 14 y ss.).

${ }^{15}$ Art. 55 , inc. $1^{\circ}$, del Reglamento.

${ }^{16}$ Cfr. LAGUNA, José, La autorización administrativa, Cizur Menor: Thomson Reuters, 2006, p. 160. Sobre la distinción entre actos administrativos favorables y desfavorables véase BERMÚDEZ, Jorge, Derecho administrativo general, $3^{\mathrm{a}}$ edición, Santiago: Thomson Reuters, 2014, p. 144; BOCANEGRA, Lecciones, cit. nota ${ }^{\circ} 14$, pp. 51 y ss.
} 
exención, dependiendo de si el administrado es titular o no de un derecho a que se le conceda la autorización, en caso de reunirse los correspondientes presupuestos. ${ }^{17}$ Tratándose del primer tipo de sistemas, el ordenamiento jurídico no impide la realización de una actividad porque esta represente una acción no deseada en general (por ejemplo, la construcción de edificios), sino porque es necesario verificar, previamente, que se cumplen determinados presupuestos. ${ }^{18} \mathrm{Si}$ estos concurren, existe un derecho a que se conceda la autorización administrativa. ${ }^{19}$ En este tipo de sistemas, el impedimento para llevar a cabo la respectiva actividad solo perdura hasta que, en el procedimiento de autorización, se constata que se satisfacen los presupuestos correspondientes, caso en el cual la Administración debe otorgar el permiso. ${ }^{20}$ Por el contrario, tratándose de los sistemas de control represivo con reserva de exención, el ordenamiento jurídico impide, en general, la realización de una actividad (por ejemplo, el porte de armas de fuego), pero la autoriza en casos de excepción. En este tipo de sistemas, no se es titular de un derecho a que se conceda la respectiva autorización si se cumplen ciertos presupuestos, sino únicamente de un derecho a exigir que la Administración adopte una decisión discrecional no arbitraria. ${ }^{21}$

El otorgamiento de un registro sanitario, que permite distribuir un medicamento en Chile, está sometido a un sistema de control represivo con reserva de exención, puesto que el Reglamento de productos farmacéuticos no contiene una enumeración de requisitos que, en caso de reunirse, hagan surgir un derecho a la concesión del registro; ${ }^{22}$ antes bien, esta concesión queda sujeta a la discrecionalidad del Instituto de Salud Pública, la que, en todo caso, no puede ser arbitraria. La reglamentación extrapenal chilena en materia de productos farmacéuticos se diferencia, por ejemplo, de las respectivas legislaciones española y alemana, que sí están concebidas como sistemas de control preventivo con reserva de permiso. Así, el artículo 10.1 del Real Decreto Legislativo 1/2015, de 24 de julio, señala que la Agencia Española de Medicamentos y Productos Sanitarios deberá otorgar la autorización para poner en el mercado el respectivo medicamento, si se satisfacen determinadas condiciones que la misma norma se encarga de enumerar. Por su parte, el párrafo 2 del $\S 25$ de la Arzneimittelgesetz alemana describe detalladamente las únicas causales que permiten denegar la autorización para distribuir un producto farmacéutico, las que, si no concurren, obligan a la Administración a otorgar el correspondiente permiso. ${ }^{23}$ En cambio, el Reglamento de productos farmacéuticos chileno no contiene normas de las cuales se pueda desprender la existencia de un derecho a que se conceda el respectivo registro sanitario, en caso de reunirse determinadas condiciones. ${ }^{24}$

\footnotetext{
${ }^{17}$ Así, expresamente, SACH, Karsten, Genehmigung als Schutzschild?: die Rechtsstellung des Inhabers einer immissionsschutzrechtlichen Genehmigung, Berlin: Duncker \& Humblot, 1994, p. 40.

${ }^{18}$ MAURER, Hartmut; WALDHOFF, Christian, Allgemeines Verwaltungsrecht, 19a edición, München: C.H. Beck, 2017, § 9 número marginal 52.

${ }^{19}$ BRAUER, Jürgen, Die strafrechtliche Behandlung genehmigungsfähigen, aber nicht genehmigten Verhaltens, Berlin: Duncker \& Humblot, 1988, p. 47; KORTE, Stefan, "§ 46 Arten der Verwaltungsakte”, en:

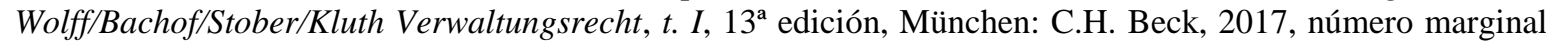
39.

${ }^{20}$ En este sentido MAURER/WALDHOFF, Allgemeines Verwaltungsrecht, cit. nota $\mathrm{n}^{\circ} 18, \S 9$ número marginal 52. Así ocurre, por ejemplo, con los permisos urbanísticos. Conforme al inc. $2^{\circ}$ del art. 1.4.1 de la Ordenanza General de la Ley General de Urbanismo y Construcciones, el "Director de Obras Municipales concederá el permiso de urbanización o edificación si los antecedentes acompañados cumplen con el Instrumento de Planificación Territorial y demás disposiciones de la Ley General de Urbanismo y Construcciones y la presente Ordenanza..." (el destacado es nuestro).

${ }^{21}$ En este sentido SACH, Genehmigung, cit. nota ${ }^{\circ} 17$, p. 40.

${ }^{22}$ Cfr. MAYER, Strafrechtliche Produktverantwortung, cit. nota n ${ }^{\circ}$ 7, p. 53 (con nota al pie 159).

${ }^{23}$ Acerca del antagonismo en que se encuentran los conceptos de "discrecionalidad" y "arbitrariedad", y los límites a los que se ha de someter la discrecionalidad administrativa véase GARCÍA DE ENTERRÍA, Eduardo; FERNÁNDEZ, Tomás-Ramón, Curso de Derecho Administrativo, t. I, 17 $7^{\mathrm{a}}$ edición, Cizur Menor: Thomson Reuters, 2015, pp. 504 y ss.

${ }^{24}$ Es cierto que el art. 47 del Reglamento señala que "de ser favorables las evaluaciones practicadas" por el Instituto de Salud Pública, "se otorgará el registro sanitario"; sin embargo, esta disposición no describe presupuestos más o menos detallados que den lugar a un derecho a la concesión del registro, como sí lo hacen (directa o indirectamente) las legislaciones española y alemana en materia de productos farmacéuticos. Además, dicho art. 47 pareciera estar concebido más bien para garantizar que el otorgamiento de la autorización administrativa se verifique en un tiempo prudente para el administrado, al aludir la disposición a
} 


\section{La incardinación dogmática y los efectos del otorgamiento de un registro sanitario en el injusto de los delitos culposos de homicidio y lesiones}

Corresponde a continuación responder la pregunta relativa a la ubicación que tiene, en la estructura de los delitos imprudentes de homicidio o lesiones, el acto administrativo que autoriza la distribución de un producto farmacéutico. Indisolublemente conexos a esta cuestión, se encuentran los efectos que produce tal acto en el injusto de dichos delitos, en concreto: ¿se trata de un elemento que excluye la tipicidad de la conducta o su antijuricidad? ${ }^{25}$

La ubicación en la estructura del delito de las autorizaciones administrativas ha sido objeto de un intenso debate en el Derecho penal alemán y español. Al respecto, se ha controvertido, precisamente, si el permiso estatal, en cuanto especial forma de autorización para crear riesgos, elimina la tipicidad de una conducta o bien su carácter de antijurídica. ${ }^{26}$ Se trata de una discusión con consecuencias importantes en materia de dolo y error. ${ }^{27}$ Además, la correcta ubicación de las autorizaciones administrativas en el injusto permite conservar el valor cognoscitivo y la significación didáctica de una teoría del delito dotada de coherencia interna, ${ }^{28}$ que se verían afectados si aquellos actos se incardinaran equivocadamente.

Pues bien, sobre la incardinación dogmática de las autorizaciones estatales solo existe consenso doctrinario respecto a lo siguiente: en los tipos penales que sancionan la realización de una conducta sin contar con la correspondiente autorización administrativa (por ejemplo, manejar sin licencia profesional) ${ }^{29}$, esta representa un elemento de la tipicidad concebido de manera negativa; luego, si el sujeto realiza el comportamiento contando con la respectiva autorización, la acción no será típica. ${ }^{30}$ En cambio, tratándose de

un "plazo total de seis meses contados desde la fecha de pago del arancel correspondiente". Por otra parte, la detallada enumeración de documentos que el solicitante del registro sanitario tiene que presentar, y que está contenida en los arts. 28 a 36 del Reglamento, en ningún caso constituye un listado de presupuestos que otorguen un derecho a la concesión del registro; se trata, únicamente, de la descripción de los antecedentes indispensables para comprobar la calidad, seguridad y eficacia del producto farmacéutico.

${ }^{25}$ Existe acuerdo en que una autorización administrativa no puede operar como causa de exclusión de la culpabilidad; en este sentido, por ejemplo, HÜBENETT, Carolin, Rechtswidrige behördliche Genehmigung als Rechtfertigungsgrund - ein gelöstes strafrechtliches Problem? - Dargestellt an $\$ 324$ StGB (Gewässerverunreinigung), Bonn: sin editorial, 1986, p. 44.

${ }^{26}$ Véase la panorámica general contenida en DE LA MATA, Norberto, Protección penal del ambiente y accesoriedad administrativa - Tratamiento penal de comportamientos perjudiciales para el ambiente amparados en una autorización administrativa ilícita, Barcelona: Cedecs, 1996, pp. 102 y ss.; KÜHL, Kristian, Strafrecht Allgemeiner Teil, $8^{\text {a }}$ edición, München: Vahlen, 2017, § 9 números marginales 119 y ss.; SALIGER, Frank, "Vorbemerkung zu den $\S 3324$ ff.", en: SATZGER, Helmut; SCHLUCKEBIER, Wilhelm

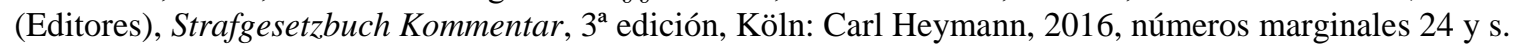

${ }^{27}$ KÜHL, Strafrecht, cit. nota n ${ }^{\circ} 26, \S 9$ número marginal 120; SALIGER, Frank, Umweltstrafrecht, München: Vahlen, 2012, número marginal 96. Así, por ejemplo, si un sujeto supone erróneamente que no cuenta con la respectiva autorización administrativa para realizar una actividad, y aquella se estima como un elemento de la tipicidad, entonces se verificará un supuesto de tentativa inidónea (en este sentido HEGHMANNS, Michael, Grundzüge einer Dogmatik der Straftatbestände zum Schutz von Verwaltungsrecht oder Verwaltungshandeln, Berlin: Duncker \& Humblot, 2000, p. 178 con nota al pie 152); en cambio, si la autorización se considera una causa de justificación, el delito se podría castigar, dado el caso, a título de tentativa (sobre la solución de la tentativa en los casos de ausencia de elementos de justificación subjetivos véase BEULKE, Werner; SATZGER, Helmut, Strafrecht Allgemeiner Teil - Die Straftat und ihr Aufbau, 47 edición, Heidelberg: C.F. Müller, 2017, número marginal 406; MURMANN, Grundkurs, cit. nota n ${ }^{\circ} 1$, $\$ 25$ números marginales 6 y ss.).

${ }^{28}$ Cfr. FRISCH, Wolfgang, Tatbestandsmäßiges Verhalten und Zurechnung des Erfolgs, Heidelberg: Müller, 1988, p. 44, quien destaca, a propósito de la ubicación correcta del "peligro desaprobado" como problema de conducta típica o de imputación de resultados, la importancia que tiene el valor cognoscitivo y la significación didáctica de un sistema dogmático dotado de coherencia interna.

${ }^{29}$ Art. 194 , inc. $1^{\circ}$, de la Ley de Tránsito.

${ }^{30}$ Así, por ejemplo, HÜWELS, Hermann, Fehlerhafter Gesetzesvollzug und strafrechtliche Zurechnung, Berlin: Duncker \& Humblot, 1986, p. 36; ROXIN, Claus, Strafrecht Allgemeiner Teil, t. I, $4^{\text {a }}$ edición, 
aquellos tipos que sancionan la realización de un comportamiento sin referencia explícita a la ausencia de un permiso, la ubicación en el injusto de la autorización administrativa es un asunto muy debatido. Así ocurre, precisamente, con los delitos imprudentes de los arts. 490, 491 y 492 del Código Penal, que castigan la lesión a bienes jurídicos con independencia de la falta de un permiso estatal. Tratándose de esta clase de delitos, un sector dominante de la doctrina se inclina por la "teoría diferenciadora". 31

\subsection{La teoría diferenciadora: ¿el otorgamiento de un registro sanitario como causa de justificación?}

De acuerdo con la teoría diferenciadora, la posición que ocupa una autorización administrativa en la estructura del delito depende de si aquella se refiere a un sistema de control preventivo con reserva de permiso, o bien, a un sistema de control represivo con reserva de exención. Como se adelantó, tratándose de los sistemas de control preventivos, existe un derecho del ciudadano a que se le conceda la autorización, en caso de reunirse los presupuestos contemplados en la respectiva regulación administrativa. Esta regulación considera la conducta que debe ser autorizada en caso de concurrir esos presupuestos como, en general, socialmente valiosa y por lo tanto como tolerada. ${ }^{32}$ En cambio, tratándose de los sistemas de control represivos, la conducta objeto de control estatal se considera regularmente como no deseada. ${ }^{33}$ Solamente en casos excepcionales, cuando concurren circunstancias que hacen privilegiar determinados intereses por sobre la necesidad de defensa frente a peligros, es posible autorizar el comportamiento prohibido. ${ }^{34}$ Pues bien, las relaciones regla general-excepción, que pueden reconocerse en los sistemas de control preventivos y represivos, serían susceptibles de extrapolarse a la relación regla generalexcepción que existe entre tipicidad y antijuricidad. ${ }^{35}$ En consecuencia, las autorizaciones dictadas en el marco de controles preventivos excluirían la tipicidad del comportamiento, puesto que recaerían en acciones que en principio son adecuadas socialmente. En cambio, los permisos excepcionales dictados en el contexto de controles represivos representarían causas de justificación. ${ }^{36}$

München: C.H. Beck, 2006, § 10 número marginal 32 (hay versión castellana de la segunda edición de 1994: Derecho penal Parte general (trad. LUZÓN, Diego-Manuel et al, Madrid: Civitas, 1997)). Para HEGHMANNS, Grundzüge, cit. nota n ${ }^{\circ} 27$, p. 173, en esta clase de tipos penales el injusto no radica en la mera desobediencia a la autoridad, ni tampoco en el peligro inmediato para bienes jurídicos, sino en el ataque a la capacidad de funcionamiento de un "control de entrada" respecto de conductas potencialmente peligrosas. ${ }^{31}$ Rönnau prefiere hablar de "solución diferenciadora", RÖNNAU, Thomas, "Vorbemerkungen zu den $\S \S$ 32", en: LAUFHÜTTE, Heinrich Wilhelm et al (Editores), Strafgesetzbuch Leipziger Kommentar Großkommentar, t. 2, 12ª edición, Berlin: Walter de Gruyter, 2006, número marginal 274.

${ }^{32}$ DE LA MATA, Norberto; DE LA MATA, Ignacio, "La figura de la autorización en la lesión de bienes jurídico-penales de carácter supraindividual”, en: LÓPEZ, Jacobo; ZUGALDÍA, José (Editores), Dogmática y ley penal - Libro homenaje a Enrique Bacigalupo, vol. I, Madrid: Marcial Pons, 2004, pp. 483-504, p. 502; WINKELBAUER, Wolfgang, Zur Verwaltungsakzessorietät des Umweltstrafrechts, Berlin: Duncker \& Humblot, 1985, p. 20.

${ }^{33}$ El rendimiento del criterio para distinguir entre sistemas de control preventivo con reserva de permiso y de control represivo con reserva de exención, consistente en si se está o no frente a conductas socialmente valiosas, puede ser muy dudoso en el caso concreto. Así, por ejemplo, tradicionalmente se ha planteado que el porte de armas de fuego está sometido a un régimen de control represivo, pero ¿no es acaso deseable socialmente, para la efectiva prevención de robos, que los guardias que trabajan en empresas de transporte de valores porten pistolas? (véase HEGHMANNS, Grundzüge, cit. nota $\mathrm{n}^{\circ} 27, \mathrm{p}$. 149). Por otra parte, la conducción de vehículo se ha considerado siempre como una actividad sometida a un régimen de control preventivo con reserva de permiso; sin embargo, a partir de cierto tamaño del parque automotriz, la actividad de conducción de automóviles conlleva enormes costos ecológicos y económicos, por lo que su utilidad social decae drásticamente (HEGHMANNS, Grundzüge, cit. nota n 27, pp. 149 y s.).

${ }^{34}$ Cfr. FORTUN, Steffen, Die behördliche Genehmigung im strafrechtlichen Deliktsaufbau, Berlin: Duncker \& Humblot, 1998, p. 38.

${ }^{35}$ MAYER, Strafrechtliche Produktverantwortung, cit. nota ${ }^{\circ}$ 7, p. 328.

${ }^{36}$ De esta opinión, entre otros, ALEXANDER, Thorsten, Die strafrechtliche Verantwortlichkeit für die Wahrung der Verkehrssicherungspflichten in Unternehmen, Herbolzheim: Centaurus, 2005, p. 85; BRAUER, Die strafrechtliche Behandlung, cit. nota ${ }^{\circ} 19$, pp. 52 y s.; DE LA MATA, "La figura", cit. nota ${ }^{\circ}{ }^{32}$, pp. 502 y s.; HÜBENETT, Rechtswidrige, cit. nota ${ }^{\circ}$ 25, p. 46; PAEFFGEN, Hans-Ullrich; ZABEL, Benno, "Vorbemerkungen zu $\S \S 32$ ff", en: KINDHÄUSER, Urs; NEUMANN, Ulfrid; PAEFFGEN, Hans-Ullrich (Editores), Nomos Kommentar Strafgesetzbuch, t. 1, 5 a edición, Baden-Baden: Nomos, 2017, número 
CONTRERAS, Lautaro, "La autorización administrativa como pauta para determinar la conducta típica en los delitos culposos de homicidio y lesiones: una cuestión de orden primario de comportamiento ejemplificada a través del otorgamiento de registros sanitarios".

Como se explicó, la regulación extrapenal que rige el otorgamiento de registros sanitarios está concebida como un sistema de control represivo con reserva de exención, puesto que no existe un derecho a que se autorice la distribución de un producto farmacéutico; antes bien, la concesión de un registro sanitario queda sujeta a la discrecionalidad del ISP. Sin embargo, no puede sostenerse, tal como lo harían los partidarios de la "teoría diferenciadora", que el registro de un medicamento represente una causa de justificación en los delitos culposos de homicidio y lesiones. ${ }^{37}$ Como se verá en el apartado siguiente (infra 2.2.), una solución semejante desconoce no solo la relación existente entre las regulaciones extrapenales y las autorizaciones administrativas, sino también la relevancia que las autorizaciones adquieren para la ponderación de intereses en el desarrollo de la libertad y en la conservación de bienes jurídicos; tal ponderación resulta básica para la configuración del comportamiento típico en los delitos culposos. ${ }^{38}$ Por eso, tanto en los supuestos de controles represivos como en los casos de controles preventivos, la autorización administrativa puede operar como un elemento que excluye la tipicidad de la conducta.

A continuación, examinaremos detalladamente la incardinación dogmático-sistemática y los efectos del registro sanitario en el comportamiento típico de los delitos culposos de homicidio y lesiones. Para ello, resulta necesario centrar nuestra atención primeramente no en las conductas autorizadas por actos administrativos, como ocurre con el otorgamiento de registros sanitarios, sino en aquellos comportamientos que están permitidos por reglamentaciones extrapenales y los efectos que estas despliegan en el plano del injusto de conducta. Las conclusiones a las que arribemos a propósito de estos efectos serán especialmente útiles para aquellos comportamientos autorizados por actos administrativos, puesto que existen estrechos vínculos entre las reglamentaciones extrapenales y los actos administrativos: como veremos, estos últimos simplemente ejecutan las normas extrapenales (en el caso de los controles preventivos) o bien las concretan (tratándose de los controles represivos). ${ }^{39}$

\subsection{El vínculo entre las reglamentaciones extrapenales y las autorizaciones administrativas como elemento decisivo para la incardinación dogmática y los efectos del otorgamiento de un registro sanitario}

Existen varios casos en los cuales el propio ordenamiento extrapenal permite en general la realización de determinadas conductas que pueden implicar riesgos para bienes jurídicos, considerándose estos riesgos como tolerados. Así, por ejemplo, en relación con la vida y salud individual, la ley permite el expendio de bebidas alcohólicas a terceros (mayores de 18 años), aunque esta actividad pueda dar lugar a una conducción deficiente de vehículos motorizados, que ocasione un resultado lesivo en el tráfico vial. ${ }^{40}$ Respecto del bien jurídico "confianza de los inversores bursátiles en la verosimilitud de la formación de precios", el Derecho positivo autoriza la realización de ciertas actividades de estabilización de valores pecuniarios, de acuerdo con las reglas de carácter general que imparta la

marginal 201; RÖNNAU, "Vorbemerkungen zu den $\S \S 32$ ", cit. nota n ${ }^{\circ} 31$, número marginal 274; SALIGER, Umweltstrafrecht, cit. nota n ${ }^{\circ}$ 27, número marginal 97; TIEDEMANN, Klaus; ENGELHART, Marc, Wirtschaftsstrafrecht, $5^{\text {a }}$ edición, München: Vahlen, 2017, números marginales 382 y s.; WINKELBAUER, Zur Verwaltungsakzessorietät, cit. nota $\mathrm{n}^{\circ} 32$, pp. 20 y s.

${ }^{37}$ En el contexto de los casos de responsabilidad penal por el producto, la autorización para distribuir medicamentos tendría relevancia en el injusto de los delitos culposos de los arts. 490 y 492 del Código Penal (en relación con los respectivos ilícitos contra las personas), que son las normas de sanción aplicables a los casos de muertes o lesiones imprudentes que tienen su origen en productos defectuosos.

${ }^{38}$ FRISCH, Wolfgang, Verwaltungsakzessorietät und Tatbestandsverständnis im Umweltstrafrecht, Heidelberg: C.F. Müller, 1993, p. 47.

${ }^{39}$ Cfr. FRISCH, Verwaltungsakzessorietät, cit. nota n ${ }^{\circ} 38$, p. 34.

${ }^{40}$ La única actividad prohibida por el ordenamiento jurídico es el expendio de bebidas alcohólicas a personas mayores de 18 años en manifiesto estado de ebriedad o a determinados funcionarios públicos (cfr. art. 41 de la Ley $\left.\mathrm{N}^{\mathrm{o}} 19.925\right)$. 
Comisión para el Mercado Financiero. ${ }^{41}$ En relación con el bien jurídico "propiedad intelectual", la ley permite a las bibliotecas que no tienen fines de lucro, la reproducción de obras que no se encuentren disponibles en el mercado, ${ }^{42}$ etc. Conductas semejantes, que están permitidas por el orden primario extrapenal, representan acciones que en ningún caso pueden ser consideradas como disvaliosas frente al mundo de los bienes jurídicos, ${ }^{43}$ por lo cual solo cabe calificarlas como conductas atípicas, en el sentido de representar comportamientos que no crean riesgos jurídicamente desaprobados. ${ }^{44}$ Se trata de conductas que forman parte de la libertad general de actuación, u otra libertad garantizada constitucionalmente, y que no pueden ser penalizadas por el orden sancionatorio, a través de la aplicación de los arts. 490 o 492 del Código Penal, del art. 59 letra e) de la Ley $\mathrm{N}^{\circ}$ 18.045 o del art. 79 a) de la Ley $\mathrm{N}^{\mathrm{o}} 17.336$, respectivamente. ${ }^{45}$ La imposición de una sanción criminal, cuya finalidad es restablecer la vigencia del Derecho quebrantado, presupone siempre la lesión de un deber de conducta ${ }^{46}$ de tal lesión no se puede hablar si el sujeto simplemente ha ejercido su libertad jurídicamente reconocida. ${ }^{47}$

También en los supuestos de control preventivo con reserva de permiso, esto es, en los casos en los cuales existe un derecho a que, de reunirse los correspondientes requisitos, se conceda la autorización administrativa, el comportamiento permitido a través del acto estatal pasa a formar parte de la libertad general de actuación, y no puede ser considerado como típico. Piénsese en el siguiente ejemplo: la Administración autoriza habitar un edificio de departamentos, otorgando la recepción definitiva del inmueble; el permiso se concede luego de comprobarse que se satisface el cumplimiento de una serie de condiciones de seguridad, entre las que se encuentran aquellas para combatir incendios. ${ }^{48} \mathrm{El}$ peligro para la vida y salud de los habitantes del edificio, que tenga su origen en el fuego, y

\footnotetext{
${ }^{41}$ Véase el art. 52, inc. $2^{\circ}$, de la Ley $\mathrm{N}^{\mathrm{o}}$ 18.045. Acerca del bien jurídico protegido en los delitos de manipulación bursátil véase SCHRÖDER, Christian, "2. Kapitel Straf- und Bußgeldtatbestände im BörsG und WpHG”, en: ACHENBACH, Hans et al (Editores), Handbuch Wirtschaftsstrafrecht, $4^{\text {a }}$ edición, Heidelberg: Müller, 2015, pp. 1286-1366, p. 1294.

${ }^{42}$ Véase art. 71 I y ss. de la Ley $\mathrm{N}^{\circ} 17.336$.

${ }^{43}$ FRISCH, Verwaltungsakzessorietät, cit. nota $\mathrm{n}^{\circ} 38$, p. 35.

${ }^{44}$ Se podría plantear que el expendio de bebidas alcohólicas, la actividad de estabilización de precios o la reproducción de obras que no están disponibles en el mercado, son casos de "ejercicio legítimo de un derecho" (art. 10 número 10 del Código Penal) y que las normas extrapenales que autorizan tales acciones operarían como causas de justificación, no de atipicidad (sobre la naturaleza de la causa de exención de responsabilidad del "ejercicio legítimo de un derecho" véase COUSO, Jaime, "Art. 10 n 10", en: COUSO, Jaime; HERNÁNDEZ, Héctor (Editores), Código Penal comentado, Santiago: Legal Publishing, 2011, pp. 260-266, p. 263). Pero esto no sería correcto, puesto que las acciones mencionadas están permitidas por la ley al margen del contexto en que se despliegan, por lo tanto, se trata de comportamientos atípicos (sobre la idea de que es el contexto de la acción (= la situación de justificación) lo que convierte la conducta típica en justificada JAKOBS, Günther, Strafrecht Allgemeiner Teil, $2^{a}$ edición, Berlin: Walter de Gruyter, 1991, Sección 7, número marginal 41, y Sección 11, número marginal 1; hay versión castellana de la segunda edición de 1991: Derecho penal Parte general (trad. CUELLO, Joaquín; SERRANO, José, Madrid: Marcial Pons, 1997)).

${ }^{45}$ Cfr. BRÄUTIGAM-ERNST, Stephanie, Die Bedeutung von Verwaltungsvorschriften für das Strafrecht, Baden-Baden: Nomos, 2010, pp. 328 y s., y 339; FRISCH, Verwaltungsakzessorietät, cit. nota n ${ }^{\circ}$ 38, p. 8; específicamente para el ámbito del Derecho penal ambiental FELIX, Dagmar, Einheit der Rechtsordnung Zur verfassungsrechtlichen Relevanz einer juristischen Argumentationsfigur, Tübingen: Mohr Siebeck, 1998, p. 23. Sí puede ocurrir, por el contrario, que conductas prohibidas por el ordenamiento primario no sean castigadas penalmente; esto no es sino la consecuencia del carácter fragmentario de la intervención penal.

${ }^{46}$ Destaca la infracción a una norma de conducta como el presupuesto básico de cualquier hecho punible FRISCH, Verwaltungsakzessorietät, cit. nota $\mathrm{n}^{\circ} 38$, p. 10; de acuerdo con él WEI $\beta$, Die rechtliche Gewährleistung, cit. n ${ }^{\circ}$ 7, p. 494.

${ }^{47}$ Como ha puesto de relieve SCHWARZ, Andreas, "Zum richtigen Verständnis der Verwaltungsakzessorietät des Umweltstrafrechts”, GA (1993), pp. 318-328, p. 319, para que el Derecho penal cumpla con eficacia su tarea de estabilización normativa y no acabe desorientando al ciudadano, es indispensable que, previo a la aplicación de las normas de sanción penal, se hayan lesionado las respectivas normas de conducta.

${ }^{48}$ La recepción definitiva consiste en una autorización administrativa que permite habitar o destinar a uso un inmueble (véanse arts. 144 y 145 de la Ley General de Urbanismo y Construcciones). La actividad de la construcción de casas o edificios representa, como vimos en supra 1.2. un supuesto de control preventivo con reserva de permiso (cfr. inc. $2^{\circ}$ del art. 1.4.1 de la Ordenanza General de la Ley General de Urbanismo y Construcciones; véase además nota supra 20).
} 
que subsista de manera residual pese al cumplimiento de las medidas contra incendios aprobadas, ha de considerarse como tolerado y excluirse, entonces, del ámbito de la conducta típica de los arts. 490 o 492 del Código Penal, en relación con los correspondientes delitos contra las personas. Ciertamente, en la medida que una ley o un reglamento permite (en caso de cumplirse ciertas condiciones o presupuestos que debe verificar la Administración) un determinado comportamiento, el orden primario expresa que esa conducta pertenece al ámbito de libertad (general de actuación, a desarrollar actividades económicas, de trabajo, etc.) del titular del permiso. ${ }^{49} \mathrm{Al}$ mismo tiempo, el ordenamiento extrapenal indica que los peligros creados por el comportamiento permitido (a través del acto administrativo) no constituyen riesgos que el Derecho quiera eliminar o disminuir. ${ }^{50}$ Luego, se trata de riesgos para los bienes jurídicos que no pueden quedar comprendidos por el ámbito del respectivo tipo penal. Esta solución coincide con la teoría diferenciadora, según la cual, en los casos de controles preventivos con reserva de permiso, la conducta autorizada por la Administración no es típica. Sin embargo, es incorrecto sostener, como lo hacen los defensores de esta teoría, ${ }^{51}$ que el fundamento decisivo para que la conducta no cree riesgos desaprobados (y, por lo tanto, no sea típica) radique en el acto administrativo autorizante. ${ }^{52}$ Antes bien, la atipicidad de la conducta respectiva encuentra su razón principal en que la reglamentación extrapenal incardina el comportamiento en el ámbito de la libertad de acción del sujeto, y considera que los peligros que este crea no son jurídicamente relevantes para el correspondiente tipo penal; no es la autorización, sino la decisión normativa tomada previamente por la reglamentación extrapenal (es decir, la decisión de autorizar la actividad en caso de cumplirse los respectivos requisitos), la que hace que estemos frente a una conducta no típica. ${ }^{53}$

Tratándose de los supuestos de control represivo con reserva de exención, pareciera difícil sostener a primera vista que estemos frente a conductas atípicas, puesto que el ordenamiento extrapenal no describe los presupuestos bajo los cuales el respectivo comportamiento debería aprobarse. Pareciera que nos encontramos frente a conductas cuya lesividad frente al mundo de los bienes jurídicos solo desaparece a través del acto autorizante; se trataría, por tanto, de comportamientos que son típicamente disvaliosos y que solo perderían ese carácter a través del acto emitido por la autoridad. ${ }^{54}$ Sin embargo, y como acertadamente se ha destacado, esta es una imagen errada: cuando, en un determinado ámbito, el ordenamiento jurídico prescinde de contemplar un derecho al otorgamiento de un permiso estatal (bajo la concurrencia de determinados presupuestos), no es que el ordenamiento quiera considerar todas las conductas de aquel ámbito como materialmente prohibidas. ${ }^{55}$ Tampoco significa que la facultad discrecional que se le concede a la Administración de emitir el permiso tenga la función de legitimar (teniendo en cuenta el contexto en que se realiza la conducta) ${ }^{56}$ aquello que está en principio prohibido o jurídicamente desaprobado, operando el acto entonces como una causa que excluye la antijuricidad. ${ }^{57}$ Que el Derecho administrativo no fije de manera concluyente los presupuestos que deben reunirse para el otorgamiento de un permiso, y deje a la discreción de la autoridad su concesión, solo refleja que, en atención a la gran diversidad de casos, a su complejidad y a los continuos cambios de los criterios científico-técnicos de valoración, no siempre es posible formular, en el respectivo ámbito, reglas exhaustivas y concluyentes; debido a esa limitación a que se ve enfrentado el Derecho positivo, este pone a disposición

\footnotetext{
${ }^{49}$ Así FRISCH, Verwaltungsakzessorietät, cit. nota n o 38, pp. 40 y s.; cfr. también HÜWELS, Fehlerhafter Gesetzesvollzug, cit. nota $\mathrm{n}^{\circ} 30$, p. 37.

${ }^{50}$ FRISCH, Verwaltungsakzessorietät, cit. nota $\mathrm{n}^{\mathrm{o}} 38$, p. 41.

${ }^{51}$ Véase, por ejemplo, PAEFFGEN, "Vorbemerkungen zu $\S \S 32$ ff”, cit. nota n ${ }^{\circ} 36$, número marginal 201.

${ }^{52}$ FRISCH, Verwaltungsakzessorietät, cit. nota $\mathrm{n}^{\circ} 38$, pp. 42 y s.

${ }^{53}$ En este sentido FRISCH, Verwaltungsakzessorietät, cit. nota $\mathrm{n}^{\circ} 38$, p. 43; en términos similares SCHWARZ, "Zum richtigen Verständnis", cit. nota $n^{\circ} 47$, p. 321.

${ }^{54}$ En este sentido FRISCH, Verwaltungsakzessorietät, cit. nota ${ }^{\circ} 38$, p. 47.

${ }^{55}$ FRISCH, Verwaltungsakzessorietät, cit. nota $n^{\circ} 38$, p. 47.

${ }^{56}$ Véase supra nota 44.

${ }^{57}$ Así FRISCH, Verwaltungsakzessorietät, cit. nota no 38, pp. 47 y s.
} 
de la Administración determinadas pautas y criterios generales, para que ella sea la que enjuicie el caso concreto, otorgando o no el permiso para llevar a cabo la respectiva actividad o ejecutar el correspondiente comportamiento ${ }^{58}$ Esta situación es la que acontece, precisamente, tratándose de la distribución de medicamentos en el caso chileno. Teniendo en cuenta la gran variedad de productos farmacéuticos que pueden someterse a un proceso de autorización, la complejidad de los riesgos farmacológicos, y el continuo desarrollo de los conocimientos científicos y técnicos en la materia, el ordenamiento extrapenal chileno ha considerado como no posible ni deseable fijar de manera exhaustiva y rígida los requisitos que deben concurrir en cada caso para otorgar un registro sanitario. ${ }^{59}$ Dicho ordenamiento ha delegado parte de la tarea de concreción del Derecho (en lo que dice relación con estos requisitos) en aquella institución pública mejor capacitada para adquirir un conocimiento detallado de los riesgos y beneficios de cada medicamento: el Instituto de Salud Pública. Para ello, el Reglamento de productos farmacéuticos prevé pautas y criterios generales que facilitan la tarea del Instituto de concretar el ámbito de lo autorizado o no autorizado en el caso particular. El criterio general más relevante consiste en la relación riesgo-beneficio terapéutico que muestra el producto farmacéutico. ${ }^{60}$ De acuerdo con esta pauta, el Instituto ha de comparar la intensidad y la probabilidad de los efectos tanto positivos como negativos del respectivo fármaco y decidir, a continuación, si sus efectos negativos están en una relación razonable con el provecho terapéutico que puede brindar. ${ }^{61}$ A través de este criterio, el ordenamiento jurídico está en condiciones de adaptarse a la complejidad de los peligros farmacológicos, y a los avances científicos y tecnológicos en la materia, teniendo a su cargo el ISP la labor de concretar el Derecho que ha de regir en cada situación particular, autorizando o no la actividad de distribución.

Cuando el ISP ejerce sus facultades en orden a conceder o no un registro sanitario, lo que hace es establecer qué comportamientos de distribución de productos farmacéuticos, y qué correlativas afectaciones a bienes jurídicos, deben ser aprobados en interés de la libertad de acción y cuáles no. ${ }^{62} \mathrm{El}$ comportamiento tendrá que ser aprobado cuando la utilidad social

\footnotetext{
${ }^{58}$ FRISCH, Verwaltungsakzessorietät, cit. nota $\mathrm{n}^{\mathrm{o}} 38, \mathrm{p} .48$.

${ }^{59}$ Cfr. FRISCH, Wolfgang, "Ermessen, unbestimmter Begriff und Beurteilungsspielraum im Strafrecht", NJW (1973), pp. 1345-1349, p. 1347.

${ }^{60}$ El criterio de "relación riesgo-beneficio terapéutico" aparece mencionado en varios preceptos del Reglamento; así, en los arts. 59 letra a), 218, 219 y 220. Es del art. 59 letra a) del que se desprende, con relativa claridad, que solo cuando la relación riesgo-beneficio terapéutico es favorable, cabe el otorgamiento del respectivo registro sanitario. El criterio de "relación riesgo-beneficio terapéutico" constituye un criterio general que el ISP tiene en cuenta para la autorización o rechazo de la comercialización de un producto farmacéutico (véase, en este sentido, la página 9 del instructivo sobre procedimiento de registro sanitario de productos farmacéuticos, disponible en http://www.ispch.cl/sites/default/files/Instructivo\%20procedimiento\%20de\%20registro\%20de\%20productos \%20farmaceuticos..pdf [visitado el 22 de mayo de 2018]). Otros criterios y pautas generales que permiten concretar el ámbito de lo autorizado o no autorizado son las orientaciones contenidas en la farmacopea de otros países (inciso primero del art. 33 del Reglamento) o las series de informes técnicos del Comité de Expertos de la Organización Mundial de la Salud para patrones biológicos, biotecnológicos, químicos, radioactivos y otros (inciso segundo del art. 33 del Reglamento).

${ }^{61}$ Sobre el criterio de la relación riesgo-beneficio terapéutico en detalle GEORGY, Philipp, Die strafrechtliche Verantwortlichkeit von Amtsträgern für Arzneimittelrisiken - Am Beispiel öffentlich-rechtlicher Ethik-Kommissionen und des Bundesinstituts für Arzneimittel und Medizinprodukte, Berlin: Duncker \& Humblot, 2011, pp. 132 ss., así como MAYER, Strafrechtliche Produktverantwortung, cit. n ${ }^{\circ}$ 7, pp. 191 y ss. y RÄPPLE, Thilo, Das Verbot bedenklicher Arzneimittel - Eine Kommentierung zu 5 AMG, Baden-Baden: Nomos, 1991, pp. 104 y ss.; todos con ulteriores referencias. Como Freund correctamente ha destacado, en algunas ocasiones la ponderación riesgo-beneficio terapéutico del respectivo producto farmacéutico será relativamente sencilla; así ocurrirá, por ejemplo, cuando los efectos del medicamento sean claramente más dañinos que la enfermedad misma. En la mayoría de los casos, sin embargo, será problemático cuantificar exactamente la utilidad y los riesgos del producto farmacéutico, y más complejo todavía será el ejercicio de ponderación, al faltar métodos reconocidos que permitan guiarlo. Por eso, es un error considerar la ponderación riesgo-beneficio terapéutico como un mero proceso técnico, una suerte de simple cálculo matemático. Por el contrario, se trata de un ejercicio eminentemente valorativo. Véase FREUND, Georg, "§ 5 AMG”, en: JOECKS, Wolfgang; MIEBACH, Klaus (Editores), Münchener Kommentar zum Strafgesetzbuch, t. 6, 3a edición, München: C.H. Beck, 2017, número marginal 23, en: https://beck-online.beck.de [visitado el 20.08.2018].

${ }^{62}$ Acerca de los riesgos específicos que autoriza la concesión de un registro sanitario véase infra 2.3.
} 
que genere (en forma de beneficios terapéuticos del producto), sea superior a sus efectos negativos (en forma de efectos secundarios del medicamento). De este modo, el Instituto desempeña la misma tarea de delimitación entre intereses en la libertad y en la conservación de bienes jurídicos que lleva a cabo el Derecho positivo, cuando este aprueba directamente ciertas conductas, o bien, las somete a un sistema de control preventivo con reserva de permiso. ${ }^{63}$ No se trata de que cuando se concede un registro sanitario se extraiga a título excepcional una porción del ámbito de las conductas materialmente prohibidas; ${ }^{64}$ con el registro no se otorga un derecho de intervención que deban tolerar los usuarios del producto farmacéutico. ${ }^{65}$ Antes bien, cuando se concede un registro sanitario se declara (en base a los criterios generales y puntos de apoyo que entrega el Reglamento) que la conducta de distribución del respectivo medicamento pertenece al ámbito de la libertad de acción del titular de la autorización, por superar el provecho terapéutico del producto sus eventuales efectos negativos. Tal comportamiento pasa a ser una conducta no prohibida en relación con los bienes jurídicos vida y salud y, en consecuencia, no puede quedar comprendida en el ámbito típico de los delitos culposos de homicidio y lesiones. ${ }^{66}$

La circunstancia de que la resolución que otorga el registro sanitario contemple "modos" como cláusulas accesorias, esto es, imponga al titular de la autorización ciertos deberes (por ejemplo, que el respectivo folleto informativo describa determinados riesgos que pueden surgir del uso del medicamento), ${ }^{67}$ no obsta a que la conducta de comercialización se considere como aprobada. ${ }^{68}$

Cabe preguntarse si la pertenencia de la conducta autorizada por el registro sanitario al ámbito de la libertad de acción, y la consiguiente exclusión de aquella del comportamiento típico de los delitos de homicidio y lesiones, es una cuestión que se fundamenta en el acto que dicta el ISP o, más bien, en el Reglamento de productos farmacéuticos. Al respecto, cabe destacar que dicho acto lo que hace es concretizar o actualizar el Reglamento en aquella parte en que, por la complejidad de la materia y los continuos cambios de los criterios científico-técnicos de enjuiciamiento, no fue posible formular en el respectivo ámbito reglas exhaustivas y concluyentes (que regulen cada una de las distintas situaciones que pueden presentarse). ${ }^{69}$ Esta labor de concretización o actualización está sujeta a la observancia de las pautas y criterios generales que ofrece el propio Reglamento para guiar el actuar de la Administración, en especial del criterio de la relación riesgo-beneficio terapéutico. Las autoridades del ISP, en cuanto funcionarios públicos vinculados al Derecho, no toman ninguna decisión normativa autónoma en el sentido de valorar y ponderar los intereses en juego en el ámbito farmacéutico; antes bien, esas autoridades

\footnotetext{
${ }^{63}$ Cfr. FRISCH, Verwaltungsakzessorietät, cit. nota $n^{\circ} 38$, p. 49.

${ }^{64}$ Cfr. FRISCH, Verwaltungsakzessorietät, cit. nota $\mathrm{n}^{\circ} 38$, p. 49.

${ }^{65}$ Véase KAUFMANN, Armin, "Rechtspflichtbegründung und Tatbestandseinschränkung”, en: KOHLMAN, Günter (Editor), Festschrift für Ulrich Klug zum 70. Geburtstag, t. 2, Köln: Deubner, 1983, pp. 277-292, p. 282.

${ }^{66}$ La conducta de distribución de un producto farmacéutico que no cuenta con el correspondiente registro sanitario solo constituirá un comportamiento típico, en el sentido de los delitos de homicidio y lesiones corporales, cuando el producto genere riesgos para la vida y salud superiores a sus beneficios terapéuticos. Y es que el injusto de dichos delitos no consiste en la realización de un comportamiento sin contar con la correspondiente autorización administrativa (lo que solo podría dar lugar a una responsabilidad administrativo-sancionadora), sino en la creación de peligros para la vida y la salud más allá de los socialmente permitido.

${ }^{67}$ Sobre el significado de los “modos” en el Derecho administrativo véase supra nota número 14.

${ }^{68}$ Una de las características de los comportamientos que generan riesgos tolerados es que se trata de acciones que el ordenamiento jurídico aprueba en atención a su utilidad social, siempre que se cumplan determinadas condiciones de minimización de riesgos (ejemplo: los peligros que crea la conducción de vehículos motorizados se permiten en la medida que se cumpla el programa de minimización de riesgos previsto en la Ley de Tránsito).

${ }^{69}$ Cfr. FRISCH, Verwaltungsakzessorietät, cit. nota n ${ }^{\circ} 38$, p. 51.
} 
(solo) subsumen los hechos del caso concreto a la ponderación de intereses ya prevista en el Reglamento y que se haya expresada en las pautas y criterios generales referidos. ${ }^{70}$

\subsection{Acerca de los específicos riesgos autorizados a través del otorgamiento de un registro sanitario}

Corresponde abordar la cuestión relativa a cuáles son, específicamente, los riesgos para la vida y salud que deben estimarse como tolerados o permitidos con el otorgamiento de un registro sanitario. Como ha destacado la doctrina penal dedicada al estudio de las autorizaciones administrativas, los efectos de estas en la exclusión del injusto solo se refieren a un segmento de un conjunto de riesgos complejos, segmento que la Administración analizó como requisito para dictar los respectivos permisos. ${ }^{71}$ Es necesario, entonces, preguntarse acerca de cuál es la específica porción de riesgos, para la vida y salud, que deben estimarse como no disvaliosos con el otorgamiento de un registro sanitario.

La cuestión relativa a cuáles son los alcances precisos de las autorizaciones administrativas ha sido estudiada en el Derecho público bajo la rúbrica del "contenido de la regulación de las autorizaciones administrativas". ${ }^{72} \mathrm{Al}$ respecto se ha señalado que la concreción del alcance de una autorización estatal exige siempre la interpretación de esta. ${ }^{73}$ Para ello, hay que considerar algunas pautas generales. Así, siempre hay que tener en cuenta las circunstancias de peligro que fundamentaron la autorización $;{ }^{74}$ de este modo, si para adoptar la decisión la Administración no tuvo a la vista determinados riesgos, su aprobación en ningún caso podrá formar parte del contenido del acto. Su eliminación o disminución hasta límites socialmente tolerables formará parte del ámbito de competencia exclusiva del titular del permiso. Además, para fijar los peligros que un permiso aprueba hay que preguntarse acerca de cuál es el alcance que le daría a la autorización un

\footnotetext{
${ }^{70}$ Cfr. KAUFMANN, "Rechtspflichtbegründung", cit. nota $\mathrm{n}^{\circ} 65$, p. 282; MAYER, Strafrechtliche Produktverantwortung, cit. $\mathrm{n}{ }^{\circ} 7$, p. 332. En el ejercicio de su función, el ISP no solo está jurídicamente vinculado a esas pautas y criterios: las decisiones ya adoptadas también lo obligan respecto al otorgamiento o a la denegación de autorizaciones futuras, conforme al mandato de igualdad que debe cumplir la Administración (cfr. FRISCH, Verwaltungsakzessorietät, cit. nota $n^{\circ} 38$, p. 50). Según este mandato, el ISP está (auto)vinculado a las decisiones previas ajustadas a Derecho que haya adoptado en materia de otorgamiento de registros sanitarios, y no puede apartarse de ellas sin que existan razones suficientes que lo justifiquen (acerca de la importancia de la praxis previa en el ejercicio de facultades discrecionales para satisfacer el mandato de igualdad ante la ley véase KLUTH, Winfried, "§ 31 Gesetzesgebundenheit und Verwaltungsspielräume", Wolff/Bachof/Stober/Kluth Verwaltungsrecht I, $13^{\mathrm{a}}$ edición, München: C.H. Beck, 2017, número marginal 62). Podría afirmarse que en la práctica diaria de la Administración chilena la igualdad ante la ley no siempre es debidamente observada. Con todo, no puede olvidarse que el mandato de igualdad no expresa una proposición asertiva, sino una proposición prescriptiva; es decir, no describe lo que ocurre en la labor diaria de los operadores estatales, sino que prescribe lo que debería acontecer para que la actuación del Estado pueda legitimarse (cfr. en materia de garantías penales FERRAJOLI, Luigi, Derecho y razón - Teoría del garantismo penal, Madrid: Trotta, 1995, p. 92).

${ }^{71}$ ALEXANDER, Die strafrechtliche Verantwortlichkeit, cit. nota $\mathrm{n}^{\circ}$ 36, p. 85; HEINE, Günter, Die strafrechtliche Verantwortlichkeit von Unternehmen, Baden-Baden: Nomos, 1995, p. 70. La opinión de estos autores se fundamenta en la idea de la "amplitud del examen fáctico" (Sachprüfungsumfang) cuyo origen se encuentra en el Derecho administrativo (véase, por ejemplo, HERMES, Georg, "Die Wirkung behördlicher Genehmigungen: Privates Risiko oder staatliche (Mit-)Verantwortung bei veränderter Sachlage?", en: BECKER-SCHWARZE, Kathrin et al (Editores), Wandel der Handlungsformen im öffentlichen Recht / 31. Tagung der Wissenschaftlichen Mitarbeiterinnen und Mitarbeiter der Fachrichtung "Öffentliches Recht", Bremen 1991, Stuttgart: Boorberg, 1991, pp. 187-211, pp. 208 y s.).

${ }^{72}$ Sobre el "contenido de la regulación de las autorizaciones administrativas" en detalle FLUCK, Jürgen, "Die Legalisierungswirkung von Genehmigungen als ein Zentralproblem öffentlich-rechtlicher Haftung für Altlasten", Verwaltungsarchiv tomo 79 (1988), pp. 406-444, pp. 420 y ss.; HERMES, "Die Wirkung", cit. nota $\mathrm{n}^{\circ} 71$, pp. 207 y ss.

${ }^{73}$ Cfr. FLUCK, "Die Legalisierungswirkung”, cit. nota no 72, p. 421.

${ }^{74}$ Así SCHLEHOFER, Horst, "Vorbemerkung zu § 32", en: JOECKS, Wolfgang; MIEBACH, Klaus (Editores), Münchener Kommentar zum Strafgesetzbuch, t. 1, $3^{\mathrm{a}}$ edición, München: C.H. Beck, 2017, número marginal 226, en: https://beck-online.beck.de [visitado el 20.08.2018]; cfr. también OTTO, Harro, "Die strafrechtliche Verantwortung für die Verletzung von Sicherungspflichten in Unternehmen”, en: HOYER, Andreas et al (Editores), Festschrift für Friedrich-Christian Schroeder zum 70. Geburtstag, Heidelberg: C.F. Müller, 2006, pp. 339-356, p. 355.
} 
observador sensato que interpretara cuidadosamente su tenor; ${ }^{75}$ no es relevante la representación subjetiva de la autoridad que no encuentre reflejo en el tenor del acto administrativo, así como tampoco la comprensión personal del titular del permiso. ${ }^{76}$ Por último, para dilucidar cuáles son los concretos peligros que una autorización administrativa aprueba o tolera es imprescindible tener en consideración la normativa extrapenal que regula su dictación. ${ }^{77}$

De las pautas desarrolladas en el Derecho administrativo para concretar el contenido de la regulación prevista en las autorizaciones administrativas, la que resulta verdaderamente decisiva para resolver el problema que nos ocupa parece ser la última de las mencionadas. Porque si los registros sanitarios no hacen sino concretar para un caso particular el Reglamento de productos farmacéuticos, mediante la aplicación de determinados criterios generales que facilitan la delimitación entre intereses (en el desarrollo de la libertad y en la conservación de bienes), resulta claro que el alcance del registro sanitario en materia de exclusión de riesgos típicamente relevantes debe determinarse a la luz del propio Reglamento. Pues bien, a partir de la lectura de su art. 18 , inc. $1^{\circ}$, se puede inferir que la evaluación de los riesgos que lleva a cabo el ISP, antes de decidir si autoriza la distribución de un medicamento, recae en los efectos que este tiene en el organismo humano, y no en los métodos de producción que emplea la empresa farmacéutica para su fabricación o en otro tipo de aspectos organizativos (sistemas de vigilancia activa o pasiva implementados, medidas para evitar riesgos de comunicación o selección de personal no idóneo, etc.). Luego, los únicos riesgos susceptibles de ser considerados como tolerados a través del otorgamiento de un registro sanitario son aquellos que tengan alguna vinculación con los efectos del medicamento en el organismo. De los artículos 59 letra a), 218, 219 y 220 del Reglamento se desprende, por su parte, que tales riesgos no son otros que aquellos vinculados con los efectos secundarios del respectivo medicamento, los que son asumidos como no disvaliosos por el ordenamiento jurídico considerando los beneficios terapéuticos del producto. Los artículos recién citados no hacen sino positivizar la idea del riesgo permitido en el ámbito de los medicamentos. De esta forma, el Reglamento de productos farmacéuticos está dispuesto a asumir la creación de ciertos peligros para la vida o la salud (vinculados con los efectos secundarios del medicamento), en razón a su menor importancia en comparación con la utilidad social que se espera de la distribución del producto. ${ }^{78}$ Tales peligros no pueden ser considerados como típicos, en el sentido de los delitos culposos de homicidio y lesiones, puesto que (solo) son la consecuencia última del ejercicio de la libertad jurídicamente reconocida en el Reglamento, que es concretado para el caso particular a través del otorgamiento del correspondiente registro sanitario.

En contra de lo recién argumentado, en el sentido de que los registros sanitarios permiten excluir del ámbito típico de los delitos imprudentes de homicidio y lesiones aquellos riesgos para la vida y salud correspondientes a los efectos secundarios de los fármacos, se podría afirmar, tal como lo hacen algunos autores, que la Administración no estaría facultada para disponer respecto de bienes jurídicos individuales (protegidos penalmente), sino únicamente en relación a intereses colectivos. ${ }^{79}$ Solo la ley podría fijar cuáles son los riesgos socialmente permitidos para la vida o salud de las personas. ${ }^{80}$ A continuación, corresponde analizar críticamente este planteamiento.

\footnotetext{
${ }^{75}$ SCHLEHOFER, "Vorbemerkung zu § 32”, cit. nota no 74, número marginal 226.

${ }^{76}$ Expresamente HERMES, "Die Wirkung", cit. nota n ${ }^{\circ} 71$, p. 208.

${ }^{77}$ Cfr. FLUCK, "Die Legalisierungswirkung”, cit. nota $n^{\circ} 72$, p. 421.

${ }^{78}$ Cfr. HORN, "Erlaubtes Risiko", cit. nota no 7 , pp. 724 y s.

${ }^{79}$ Así BRAUER, Die strafrechtliche Behandlung, cit. nota $\mathrm{n}^{\circ} 19$, p. 110, para el caso de los controles represivos con reserva de exención; KÜHL, Strafrecht, cit. nota n ${ }^{\circ} 26, \S 9$ número marginal 136, sin distinguir la clase de controles.

${ }^{80}$ Cfr. BRAUER, Die strafrechtliche Behandlung, cit. nota n ${ }^{\circ}$ 19, p. 111.
} 


\section{4. ¿Imposibilidad de que una autorización administrativa excluya el injusto tratándose de bienes jurídicos individuales?}

Las opiniones doctrinarias, que postulan que las autorizaciones administrativas no permitirían excluir la responsabilidad penal por la lesión a bienes jurídicos individuales, han surgido en el seno de constelaciones delictivas distintas a la de los tipos imprudentes de homicidio y lesiones, que son objeto de este trabajo. Se trata de los ilícitos medioambientales y del delito previsto en el parágrafo 330a del Código Penal alemán. ${ }^{81}$

Así, en el contexto de los delitos contra el medioambiente y de las autorizaciones ambientales que concede la Administración, se ha señalado que esta solo es competente para gestionar bienes jurídicos medioambientales, permitiendo actividades industriales que pueden resultar peligrosas para esos bienes $;{ }^{82}$ el Ejecutivo no tendría ninguna potestad para disponer respecto de intereses jurídicos individuales como la vida o la salud. ${ }^{83}$ Por eso, aquel que, haciendo uso de un permiso ambiental para emitir sustancias, daña de manera negligente o dolosa la vida o la salud de los habitantes del entorno de la respectiva industria, ha de ser castigado por el delito de homicidio o lesiones corporales. ${ }^{84}$

Las argumentaciones recién expuestas, que rechazan la posibilidad de que las autorizaciones ambientales permitan excluir el injusto de los delitos de homicidio y lesiones corporales, no pueden ser extrapoladas al ámbito de los registros sanitarios. En efecto, si bien el ISP no está facultado para disponer sobre bienes jurídicos individuales, sí forma parte del ámbito de atribuciones que le entrega el propio ordenamiento extrapenal, la ponderación de intereses en la libertad de acción y en la conservación de la vida y salud de los usuarios del medicamento. De este modo, el ISP tiene la potestad de asignar al ámbito de lo permitido determinadas creaciones de riesgos vinculadas con los efectos secundarios de un medicamento, en consideración a los importantes beneficios terapéuticos que este puede proporcionar. ${ }^{85}$

En el contexto del ilícito previsto en el parágrafo 330a del Código Penal alemán, también se ha señalado que la Administración no estaría facultada para autorizar la afectación de bienes jurídicos individuales. ${ }^{86}$ Este delito castiga a quien difunda o libere sustancias que contengan veneno o que lo puedan producir y, de esta manera, cause un peligro de muerte o un grave daño a la salud de otra persona, o un peligro de daño a la salud de un gran número

\footnotetext{
${ }^{81}$ Aunque el parágrafo 330a del Código Penal alemán está ubicado en el apartado relativo a los delitos contra el medio ambiente, existe acuerdo en que la norma protege únicamente la vida y salud individual (véase, por todos, SALIGER, Frank, "§ 330a", en: SATZGER, Helmut; SCHLUCKEBIER, Wilhelm (Editores), Strafgesetzbuch Kommentar, $3^{\text {a }}$ edición, Köln: Carl Heymann, 2016, número marginal 1).

${ }^{82}$ KÜHL, Kristian; HEGER, Martin, Strafgesetzbuch Kommentar, $29^{\mathrm{a}}$ edición, München: C.H. Beck, 2018, $\S 324$ número marginal 13; RANSIEK, Andreas, "§ 324", en: KINDHÄUSER, Urs; NEUMANN, Ulfrid; PAEFFGEN, Hans-Ullrich (Editores), Nomos Kommentar Strafgesetzbuch, t. 3, $5^{\text {a }}$ edición, Baden-Baden: Nomos, 2017, número marginal 30; RUDOLPHI, Hans-Joachim, "Strafrechtliche Verantwortlichkeit der Bediensteten von Betrieben für Gewässerverunreinigungen und ihre Begrenzung durch den Einleitungsbescheid", en: KÜPER, Winfried (Editor), Festschrift für Karl Lackner zum 70. Geburtstag, Berlin: Walter de Gruyter, 1987, pp. 863-887, p. 882.

${ }^{83} \mathrm{Si}$ para la Administración fuera evidente que la conducta que se está autorizando va a desencadenar con una alta probabilidad un curso causal lesivo para la vida o salud, el respectivo acto administrativo sería nulo de pleno derecho y, en consecuencia, irrelevante para excluir una responsabilidad penal (así STERNBERGLIEBEN, "Vorbemerkungen zu den $\S \S 32$ ff.", cit. nota $\mathrm{n}^{\circ} 3$, número marginal $63 \mathrm{c}$ con ulteriores referencias).

${ }^{84}$ SCHALL, Hero, "Zur Reichweite der verwaltungsbehördlichen Erlaubnis im Umweltstrafrecht”, en: SCHÜNEMANN, Bernd et al (Editores), Festschrift für Claus Roxin, Berlin: Walter De Gruyter, 2001, pp. 927-944, p. 943; de acuerdo con él ROXIN, Strafrecht, cit. nota n ${ }^{\circ} 30, \S 17$ número marginal 68. Distinto sería el caso si el titular del permiso cree que la autorización lo faculta para producir ciertos daños a la salud; aquí podría entrar en consideración un error de prohibición.

${ }^{85}$ Cfr. KAUFMANN, "Rechtspflichtbegründung", cit. nota ${ }^{\circ}$ 65, p. 288; MAYER, Strafrechtliche Produktverantwortung, cit. ${ }^{\circ}$ 7, p. 326.

${ }^{86}$ Véase RANSIEK, Andreas, "§ 330a”, en: KINDHÄUSER, Urs; NEUMANN, Ulfrid; PAEFFGEN, HansUllrich (Editores), Nomos Kommentar Strafgesetzbuch, t. 3, 5ª edición, Baden-Baden: Nomos, 2017, número marginal 7; SALIGER, “§ 330a”, cit. nota ${ }^{\circ}$ 81, número marginal 10.
} 
de personas. Algunas de las conductas que pueden ser castigadas a través de este ilícito son: la introducción de sustancias venenosas en fuentes de agua, el envenenamiento de frutas o verduras, o el almacenamiento de basura venenosa en el suelo. ${ }^{87} \mathrm{La}$ doctrina afirma que una autorización administrativa no podría excluir el injusto de tales acciones, puesto que los poderes públicos no están facultados para conceder un permiso excepcional para liberar sustancias venenosas, que pongan en peligro de muerte o de grave daño a la salud a terceros. ${ }^{88}$

Sin embargo, resulta dudoso que, en el delito del parágrafo 330a del Código Penal alemán, la improcedencia de que una autorización administrativa excluya el injusto se explique en razón de que la Administración nunca estaría facultada para disponer sobre intereses jurídicos individuales. Tal improcedencia se fundamenta, más bien, en una consideración de naturaleza muy distinta, a saber: la de que los peligros que pretenden evitar las normas de conducta cuyo quebrantamiento presupone la aplicación del tipo (estar expuesto a beber agua envenenada o ingerir alimentos envenenados, etc.) constituyen, evidentemente, peligros a los cuales una persona sensata no se expondría a través de la propia conducta; ${ }^{89}$ en consecuencia, ha de excluirse siempre la posibilidad de que tales riesgos sean aprobados por un acto administrativo. Muy distinto es el caso del otorgamiento de registros sanitarios, en los cuales los peligros que pasan a ser permitidos por la Administración, luego del proceso de concretización de la normativa extrapenal al caso de que se trata, representan riesgos a los cuales individuos razonables no dejan de exponerse, considerando los importantes beneficios terapéuticos del medicamento autorizado.

\subsection{Resultado preliminar}

De lo expuesto es posible concluir lo siguiente: la realización de conductas autorizadas a través de actos administrativos que concretan regulaciones extrapenales forma parte del ejercicio de la libertad de acción. Este es el caso de la distribución de productos farmacéuticos, permitida a través del otorgamiento del respectivo registro sanitario, luego de que el ISP haya comprobado que los beneficios terapéuticos del medicamento son mayores que los riesgos vinculados con su uso. Los peligros para la vida y salud, derivados de los efectos secundarios del respectivo medicamento, representan riesgos tolerados, que no pueden ser considerados como típicos en el sentido de los delitos culposos de homicidio o lesiones.

\section{Los efectos en el injusto de los delitos imprudentes de homicidio y lesiones de una autorización para distribuir productos farmacéuticos que adolece de vicios}

\subsection{El problema del otorgamiento de un registro sanitario que adolece de vicios o invalidez}

Las reflexiones contenidas en la sección anterior (supra 2), concernientes a la incardinación dogmática y a los efectos en el injusto penal de las autorizaciones para distribuir medicamentos, parten del supuesto de que estos permisos representan actos administrativos válidos; este será, por lo demás, el caso más frecuente. Por actos administrativos válidos debemos entender aquellos actos que cumplen con todos los requisitos a los que el Derecho subordina su validez. ${ }^{90}$ Dentro de estos requisitos destaca el cumplimiento de las normas

\footnotetext{
${ }^{87}$ SALIGER, “§ 330a”, cit. nota n ${ }^{\circ} 81$, número marginal 4.

${ }^{88}$ En este sentido DÖLLING, Dieter, "Umweltstraftat und Verwaltungsrecht”, JZ (1985), pp. 461-469, p. 469.

${ }^{89}$ Sobre la idea de que los riesgos desaprobados son aquellos peligros frente a los cuales personas sensatas no se colocarían, en todo caso, no sin necesidad FRISCH, Tatbestandsmäßiges Verhalten, cit. nota ${ }^{\circ}{ }^{28}$, pp. 128 s., $138 \mathrm{~s}$.

${ }^{90}$ BOCANEGRA, Lecciones, cit. nota ${ }^{\circ}$ 14, p. 121. De acuerdo con la jurisprudencia asentada de la Corte Suprema, los presupuestos de validez de todo acto administrativo consisten en la investidura regular del órgano que lo dicta, la competencia de este, el cumplimiento de requisitos de forma, la ausencia de desviación de poder, la legalidad en cuanto a los motivos y la observancia de la ley de fondo aplicable (véanse las sentencias de la Corte Suprema de 07.03.18, ROL 34.277-2017, considerando 9 ${ }^{\circ}$, y de 25.04.2017, ROL
} 
jurídicas de fondo aplicables al caso. Tratándose de las autorizaciones estatales para distribuir medicamentos, esas normas jurídicas están contenidas en el Reglamento de productos farmacéuticos.

Pues bien, no puede descartarse que el Instituto de Salud Pública apruebe la distribución de un fármaco que, conforme a las normas del Reglamento, no debió haber sido autorizada, por superar los riesgos del producto sus beneficios terapéuticos. La ponderación errada de los riesgos y beneficios terapéuticos del medicamento tendrá normalmente su origen en que la empresa farmacéutica entregó antecedentes incorrectos acerca de los efectos del producto en la salud, o bien en que el Instituto evaluó deficientemente datos correctos proporcionados por la empresa. ${ }^{91}$ En uno u otro caso el otorgamiento del registro sanitario adolecerá de un vicio de nulidad, es decir, será inválido para el Derecho administrativo, por no haberse dado cumplimiento a las normas de fondo aplicables, que impedían autorizar la distribución de productos farmacéuticos cuyos riesgos fueran mayores que sus beneficios. En semejantes supuestos, se puede plantear la siguiente pregunta: ¿la conducta de distribución de medicamentos, llevada a cabo por el titular de un registro sanitario que adolece de un vicio, debe ser considerada o no como una conducta típica en el sentido de los delitos de homicidio y lesiones imprudentes? Esta cuestión no es de fácil respuesta, pues si bien una conducta de distribución de productos farmacéuticos, basada en una autorización que no debió concederse según las normas de fondo aplicables, constituye un comportamiento disvalioso frente a los bienes jurídicos vida y salud individual (y en tal sentido podría representar una creación de riesgos desaprobada), para el Derecho administrativo los actos inválidos de la Administración pueden ser jurídicamente eficaces. Por esta razón, se podría plantear que, aunque el otorgamiento de un registro sanitario sea inválido, el acto produce efectos jurídicos y, consiguientemente, autoriza a su titular para distribuir el medicamento, no pudiendo entonces esa comercialización ser sancionada por el orden secundario penal.

La idea de que los actos inválidos de la Administración pueden generar efectos jurídicos se fundamenta en la independencia que existe en el Derecho administrativo entre la eficacia y la validez de un acto. ${ }^{92}$ Ciertamente, una vez que concluye el procedimiento administrativo que les sirve de antecedente, todos los actos administrativos gozan de eficacia. ${ }^{93}$ Que los actos administrativos estén dotados de eficacia significa que son obligatorios jurídicamente, es decir, que son capaces de producir los efectos que según el Derecho persiguen, ${ }^{94}$ vinculando a todos aquellos que se encuentran comprendidos por ellos (sean órganos de la Administración Pública, funcionarios o ciudadanos particulares). ${ }^{95}$ El que un acto administrativo adolezca de un vicio o ilegalidad no conduce (de manera automática, al menos) a su falta de eficacia jurídica. La independencia entre la eficacia y la validez de los actos administrativos está consagrada en la presunción de legalidad prevista en el inc. $8^{\circ}$ del art. $3^{\circ}$ de la Ley $\mathrm{N}^{\circ} 19.880$, conforme al cual los actos se reputan legales mientras no se establezca lo contrario por un órgano público, en un procedimiento que tenga como resultado su invalidación o su nulidad. ${ }^{96}$ La falta de conexión entre la eficacia y la validez

1.623-2017, considerando $4^{\circ}$ ). Sobre las condiciones de validez de los actos administrativos en Chile véase CORDERO, Eduardo, "La nulidad de los actos administrativos y sus causales", en: FERRADA, Juan (Coordinador), IX Jornadas de Derecho Administrativo, Santiago: Thomson Reuters, 2013, pp. 189-207, pp. 195 y ss.; JARA, Jaime, La nulidad de Derecho público ante la doctrina y la jurisprudencia, Santiago: Libromar, 2004, pp. 226 y ss.

${ }^{91}$ Así MAYER, Strafrechtliche Produktverantwortung, cit. ${ }^{\circ} 7$, p. 547, quien destaca que la entrega de datos incorrectos por parte de la empresa farmacéutica puede ser consciente, y realizarse entonces con la finalidad de engañar a la Administración, o bien inconsciente, siendo en este último caso la consecuencia de la ejecución de pruebas clínicas defectuosas, que impidieron identificar en su momento determinados efectos secundarios del medicamento.

${ }^{92}$ Cfr. BELADÍEZ, Margarita, Validez y eficacia de los actos administrativos, Madrid: Marcial Pons, 1994, p. 53; BOCANEGRA, Lecciones, cit. nota n ${ }^{\circ}$ 14, pp. 121 y ss.; MADARIAGA, Mónica, Seguridad jurídica y administración pública en el siglo XXI, $2^{\text {a }}$ edición, Santiago: Editorial jurídica de Chile, 1993, p. 133.

${ }^{93}$ BERMÚDEZ, Derecho administrativo, cit. nota $\mathrm{n}{ }^{\circ} 16, \mathrm{p} .158$.

${ }^{94}$ Así, BOCANEGRA, Lecciones, cit. nota ${ }^{\circ} 14$, p. 125.

${ }^{95}$ BERMÚDEZ, Derecho administrativo, cit. nota $\mathrm{n}{ }^{\circ} 16, \mathrm{p} .158$.

${ }^{96}$ Cfr. BERMÚDEZ, Derecho administrativo, cit. nota n ${ }^{\circ} 16$, p. 158. 
de los actos de la Administración solo encuentra su límite en aquellos supuestos de nulidades de pleno derecho, es decir, en aquellos casos en los que el respectivo acto adolece de ilegalidades graves (ejemplo: incompetencia manifiesta) o bien tiene su origen en actuaciones estatales cercanas a lo delictivo $;{ }^{97}$ ninguno de estos casos extremos abarcaría el otorgamiento de un registro sanitario donde (simplemente) se ha realizado una incorrecta ponderación de la relación entre riesgo y beneficio terapéutico del producto farmacéutico.

Teniendo en cuenta, entonces, que los actos administrativos inválidos también pueden ser eficaces jurídicamente, y que, conforme al carácter accesorio del Derecho penal, las conductas autorizadas por el orden primario no pueden ser sancionadas penalmente, el otorgamiento de un registro sanitario inválido, por haberse realizado una errónea ponderación entre el riesgo y el beneficio terapéutico, tendría como consecuencia la atipicidad de la distribución del producto realizada por el titular del registro. Solo cuando este fuera invalidado o anulado por el respectivo órgano público competente, y una distribución posterior ocasionara muertes o lesiones, podría considerarse la conducta del titular del permiso como típica, en el sentido de los delitos de homicidio o lesiones. ${ }^{98}$ Pero, por otra parte, y como ya se indicó, no puede desconocerse que la distribución de un producto farmacéutico que no debió autorizarse, según las normas jurídicas de fondo, representa una conducta disvaliosa frente a los bienes jurídicos vida y salud individual y, en ese sentido, podría estimarse como un comportamiento jurídicamente desaprobado.

Para resolver el problema recién expuesto, es conveniente tener presente la discusión comparada sobre los efectos que pueden tener las autorizaciones administrativas inválidas en el injusto, debate que ha sido especialmente intenso en materia medioambiental. ${ }^{99}$ En este ámbito, la mayoría de la doctrina se inclina por alguna de estas dos soluciones: o bien se estiman como decisivas, para afirmar o negar el injusto de una conducta autorizada por un acto viciado, las valoraciones del Derecho administrativo material, con lo cual el comportamiento estaría prohibido y podría verse en él un injusto objetivo (accesoriedad al Derecho administrativo); o bien se hace hincapié en la eficacia jurídica de las autorizaciones administrativas inválidas, negándose un injusto punible, salvo que se esté frente a casos de abuso del Derecho (accesoriedad limitada al acto administrativo). A continuación, corresponde explicar y analizar críticamente ambas vías de solución.

\footnotetext{
${ }^{97}$ Véase BERMÚDEZ, Derecho administrativo, cit. nota $\mathrm{n}$ o 16, p. 163; BOCANEGRA, Lecciones, cit. nota $\mathrm{n}^{\circ}$ 14, p. 122; cfr. también MARÍN, Urbano, "Vigencia actual de la invalidación de los actos administrativos", Revista de Derecho (Consejo de Defensa del Estado), Año 1 - n ${ }^{\circ} 2$ (diciembre 2000), pp. $45-60$, pp. 54 y s. Para la teoría de la "nulidad de derecho público" cualquier tipo de vicio que sufriera el acto, independientemente de su gravedad, conduciría a una nulidad ipso iure, sin posibilidad alguna de convalidar o sanear el vicio, y sin plazo de prescripción. Sobre esta teoría SOTO, Eduardo, "La nulidad de derecho público en el derecho chileno", Revista de Derecho Público Universidad de Chile, n ${ }^{\circ} 47-48$ (1990), pp. 11-25, pp. 11 y ss.; SOTO, Eduardo, "La nulidad de derecho público referida a los actos de la Administración", Revista de Derecho, Universidad Católica de Valparaíso, XIV (1991-1992), pp. 417-431, pp. 417 y ss.; SOTO, Eduardo, "La nulidad de derecho público: su actualidad", Revista de Derecho, Universidad Católica de Valparaíso, XVIII (1997), pp. 347-355, pp. 347 y ss. Sobre la incompatibilidad de la teoría de la "nulidad de derecho público" con la presunción de legalidad de los actos administrativos, prevista en la Ley $\mathrm{N}^{\circ} 19.880$, y sostenida de manera reiterada por la jurisprudencia judicial y administrativa, véase CORDERO, "La nulidad", cit. nota $\mathrm{n}^{\circ} 90$, p. 194.

${ }^{98} \mathrm{La}$ invalidación o la nulidad de la autorización que adolece de vicios solo puede producir efectos penales ex-nunc (véase RÖNNAU, "Vorbemerkungen zu den $\S \S 32$ ", cit. nota ${ }^{\circ}{ }^{\circ} 31$, número marginal 287).

${ }^{99}$ Véase una panorámica general de la discusión en DE LA MATA, Protección penal, cit. nota n ${ }^{\circ} 26$, pp. 128 y ss.; FELIX, Einheit, cit. nota ${ }^{\circ}{ }^{4} 45$, pp. 33 y ss.; RÖNNAU, “Vorbemerkungen zu den $\S \S 32$ ”, cit. nota n ${ }^{\circ}$ 31, números marginales 278 y ss.; SALIGER, "Vorbemerkung zu den $\S \S 324$ ff.", cit. nota n ${ }^{\circ} 26$, números marginales 26 y ss.; SCHEELE, Rolf, Zur Bindung des Strafrichters an fehlerhafte behördliche Genehmigungen im Umweltstrafrecht, Berlin: Duncker \& Humblot, 1993, pp. 34 y ss.
} 


\subsection{El modelo de solución basado en la accesoriedad al Derecho administrativo}

De acuerdo con este modelo, los efectos de una autorización administrativa en la responsabilidad penal dependen exclusivamente de si aquella se ajusta a las exigencias del Derecho administrativo material, siendo irrelevante la eficacia jurídica que pueda tener un acto viciado. ${ }^{100}$ Como la Administración debe someter su acción al Derecho, no es suficiente para excluir la responsabilidad penal que la autorización administrativa sea eficaz; es indispensable, además, que se ajuste al Derecho material. ${ }^{101}$ En la medida que la autorización cumpla con las exigencias impuestas por las respectivas normas jurídicas materiales, tendrá como efecto la exclusión de la responsabilidad penal; de lo contrario, dejará subsistente el injusto objetivo del hecho. Sin embargo, en este último caso, si el titular del permiso actúa confiando en la validez del acto estatal, podrá invocar a su favor un error de permisión, puesto que habrá creído erróneamente que su conducta estaba justificada. ${ }^{102}$

Para fundar el modelo basado en la accesoriedad al Derecho administrativo se invoca el principio de unidad del ordenamiento jurídico, que obligaría a considerar las valoraciones del Derecho administrativo material como el factor decisivo para el enjuiciamiento penal de la respectiva conducta, prescindiendo de la eficacia de los permisos estatales (inválidos). ${ }^{103}$ Tal eficacia no vincularía a los tribunales penales, los que siempre estarían facultados para examinar la conformidad de una autorización con la ley; esta tarea, entonces, no se radicaría exclusivamente en la Administración o en los tribunales civiles. ${ }^{104}$ A favor del modelo de la accesoriedad al Derecho administrativo se invocan también consideraciones basadas en la justicia material (la que se vería afectada si un acto viciado excluyera el injusto) y en una adecuada protección de bienes jurídicos. ${ }^{105}$

De acuerdo con la solución basada en la accesoriedad al Derecho administrativo, el otorgamiento de un registro sanitario eficaz, pero que no debió haberse concedido según la reglamentación sustantiva aplicable, no podría excluir el injusto objetivo de los delitos culposos de homicidio y lesiones. Con todo, podría excluirse la responsabilidad penal por un error de permisión, si el respectivo titular no conocía el carácter inválido de la autorización administrativa.

\subsection{El modelo de solución basado en la accesoriedad limitada al acto administrativo}

Se trata del modelo de solución dominante en la doctrina, ${ }^{106}$ conforme al cual el criterio decisivo para valorar penalmente un comportamiento cuya realización fue autorizada por

\footnotetext{
${ }^{100}$ Entre otros GEULEN, Reiner, "Grundlegende Neuregelung des Umweltstrafrechts", ZRP (1988), pp. 323327, p. 325; SCHALL, Hero, "Umweltschutz durch Strafrecht: Anspruch und Wirklichkeit", NJW (1990), pp. 1263-1273, p. 1267; SCHWARZ, “Zum richtigen Verständnis”, cit. nota n 47, p. 321.

${ }^{101}$ Véase FELIX, Einheit, cit. nota n ${ }^{\circ} 45$, p. 41.

${ }^{102}$ Así RADEMACHER, Martin, Die Strafbarkeit wegen Verunreinigung eines Gewässers ( $\$ 324$ StGB), Frankfurt am Main: Peter Lang, 1989, pp. 72 y ss.; WINKELBAUER, Zur Verwaltungsakzessorietät, cit. nota $\mathrm{n}{ }^{\circ} 32$, pp. 72 y ss. Para otros se trataría de un error de prohibición directo (en este sentido, por ejemplo, GEULEN, "Grundlegende Neuregelung", cit. nota ${ }^{\circ}{ }^{\circ} 100$, p. 325).

${ }^{103}$ Así SCHWARZ, "Zum richtigen Verständnis", cit. nota n ${ }^{\circ}$ 47, p. 325.

${ }^{104}$ Cfr. MOHRBOTTER, Kurt, "Bindung des Strafrichters an das Handeln der Verwaltung?" JZ (1971), pp. 213-217, pp. 215 y s.

${ }^{105}$ En este sentido SCHALL, “Umweltschutz", cit. nota n ${ }^{\circ} 100$, p. 1267.

${ }^{106}$ Véase BASCUÑÁN, Antonio, "Comentario crítico a la regulación de los delitos contra el medio ambiente en el Anteproyecto de Código Penal de 2005”, en Estudios Públicos 110 (otoño 2008), pp. 1-81, p. 68, en: https://www.cepchile.cl/cep/site/artic/20160304/asocfile/20160304094528/rev110 bascunan_regulacion.pdf [visitado el 18.08.2018];; BLOY, René, "Die Straftaten gegen die Umwelt im System des Rechtsgüterschutzes", ZStW 100 (1988), pp. 485-507, pp. 502 y ss.; DÖLLING, "Umweltstraftat”, cit. nota n o 88, p. 469; KÜHL, Strafrecht, cit. nota n ${ }^{\circ}$ 26, § 9 números marginales 131 y 132.; MATUS, Jean Pierre; RAMÍREZ, Cecilia, Lecciones de Derecho penal chileno - Fundamentos y límites constitucionales del Derecho penal positivo, $3^{\text {a }}$ edición, Santiago: Legal Publishing Chile, 2015, p. 156; NIERING, Christoph, Der strafrechtliche Schutz der Gewässer, Frankfurt am Main: Peter Lang, 1993, pp. 74 y s.; STERNBERGLIEBEN, "Vorbemerkungen zu den $\S \S 32$ ff.", cit. nota ${ }^{\circ}{ }^{3}$, número marginal 63; RUDOLPHI, Hans-
} 
un acto administrativo consiste en la eficacia jurídica de este. Si al momento de realización de la conducta, la autorización administrativa era eficaz, tiene que excluirse el injusto penal, siendo irrelevante una posterior invalidación o nulidad del acto. ${ }^{107}$ Tratándose de autorizaciones sujetas a un sistema de control represivo (como ocurre con el permiso para distribuir productos farmacéuticos en el Derecho chileno), el acto eficaz pero inválido operaría como una causa de justificación. ${ }^{108}$ Según el modelo de la accesoriedad limitada al acto administrativo, la licitud de una conducta sometida a un sistema de autorización estatal no puede establecerse a partir de lo que un juez penal deduzca del Derecho administrativo material, sino solo a través de la interpretación que haya hecho de este la Administración del Estado, y que se ve reflejada en el respectivo acto administrativo eficaz. ${ }^{109} \mathrm{La}$ Administración es la única competente para concretar a través de actos administrativos las respectivas regulaciones abstractas y generales; su competencia tiene que ser reconocida por el juez penal, quien no puede negar el carácter vinculante a actos que, aunque sean inválidos, producen efectos jurídicos. ${ }^{10}$

Solo en los casos en que el titular de la autorización administrativa actúa con abuso del Derecho, el acto no producirá el efecto de exclusión de la antijuricidad. ${ }^{111}$ Habrá especialmente abuso del Derecho cuando el particular haya realizado, con anterioridad a la dictación del permiso, un comportamiento desaprobado, para así impedir que el órgano estatal encargado de examinar los respectivos riesgos adopte una decisión ajustada a Derecho (casos de exceptio doli praeteriti). ${ }^{112}$ Luego, si la autorización administrativa se obtiene mediante engaño, amenaza o soborno, el tribunal penal no podrá considerar el acto como causa de exclusión de la antijuricidad; ${ }^{113}$ lo mismo ocurrirá cuando exista colusión entre el funcionario público a cargo de conceder el permiso y el titular de este. La negación, en estos casos, del efecto de exclusión de la antijuricidad, se fundamentaría en la idea de que el abuso del Derecho también se aplica para limitar el alcance de otras causas de justificación, como ocurre con la legítima defensa, cuando el sujeto que se defiende ha provocado previamente a su agresor. ${ }^{14}$

Joachim, "Primat des Strafrechts im Umweltschutz? - 1. Teil - ", NStZ (1984), pp. 193-199, pp. 196 у 197; PAEFFGEN, "Vorbemerkungen zu $\S \S 32$ ff”, cit. nota n ${ }^{\circ} 36$, número marginal 203.

${ }_{107}$ Cfr. RUDOLPHI, "Primat des Strafrechts", cit. nota n ${ }^{\circ} 106$, p. 197.

${ }^{108}$ Así DÖLLING, "Umweltstraftat", cit. nota n ${ }^{\circ} 88$, pp. 468 y s.

${ }^{109}$ En este sentido ROGALL, Klaus, "Die Verwaltungsakzessorietät des Umweltsstrafrechts - Alte Streitfragen, neues Recht”, GA (1995), pp. 299-319, p. 315.

${ }^{110}$ Cfr. PAPIER, Hans Jürgen, "Zur Disharmonie zwischen verwaltungs- und strafrechtlichen Bewertungsmaßstäben im Gewässerstrafrecht”, NuR (1986), pp. 1-8, p. 3.

${ }^{111}$ Véase BASCUÑÁN, "Comentario crítico", cit. nota n ${ }^{\circ}$ 106, p. 68; DÖLLING, "Umweltstraftat", cit. nota $\mathrm{n}^{\circ} 88$, p. 469; KÜHL, Strafrecht, cit. nota ${ }^{\circ}$ 26, § 9 número marginal 132; STERNBERG-LIEBEN, "Vorbemerkungen zu den $\S \S 32$ ff.", cit. nota ${ }^{\circ}$ 3, número marginal 63; NIERING, Der strafrechtliche Schutz, cit. nota ${ }^{\circ} 106$, p. 75; PAEFFGEN, "Vorbemerkungen zu $\S \S 32$ ff", cit. nota ${ }^{\circ}$ '36, número marginal 203; RUDOLPHI, "Primat des Strafrechts", cit. nota n ${ }^{\circ}$ 106, p. 197. Según el modelo de solución de la accesoriedad extrema, incluso en los casos de abuso del Derecho el acto eficaz pero inválido excluiría el injusto (así HUNDT, Thomas, Die Wirkungsweise der öffentlich-rechtlichen Genehmigungen im Strafrecht, Berlin: Verlag für Wissenschaft und Forschung, 1994, p. 156; RÖNNAU, "Vorbemerkungen zu den $\S \S 32$ ”, cit. nota $\mathrm{n}^{\circ}$ 31, número marginal 286; SCHEELE, Zur Bindung des Strafrichters, cit. nota ${ }^{\circ}{ }^{9}$ 99, p. 151).

${ }^{112}$ Cfr. LENCKNER, Theodor, "Behördliche Genehmigungen und der Gedanke der Rechtsmißbrauchs im Strafrecht", en: VON GAMM, Otto-Friedrich et al (Editores), Strafrecht, Unternehmensrecht, Anwaltsrecht Festschrift für Gerd Pfeiffer zum Abschied aus dem Amt als Präsident des Bundesgerichtshofes, Köln: Carl Heymann, 1988, pp. 27-43, pp. 34 y s.

${ }^{113}$ BLOY, "Die Straftaten", cit. nota ${ }^{\circ}$ 106, p. 504; DÖLLING, "Umweltstraftat", cit. nota n ${ }^{\circ} 88$, p. 469; NIERING, Der strafrechtliche Schutz, cit. nota ${ }^{\circ} 106$, p. 75. En contra de incluir los casos de soborno a funcionarios públicos dentro de los casos de abuso del Derecho LENCKNER, "Behördliche Genehmigungen", cit. nota ${ }^{\circ} 112$, p. 37 (el abuso del Derecho solo abarcaría supuestos donde el particular impide una decisión autónoma de la autoridad, lo que no ocurre en los casos de soborno, puesto que en estos el funcionario siempre tiene la libertad de actuar con lealtad a la ley).

${ }^{114}$ Así HORN, Eckhard, "Strafbares Fehlverhalten von Genehmigungs- und Aufsichtsbehörden?", NJW (1981), pp. 1-11, p. 3; NIERING, Der strafrechtliche Schutz, cit. nota ${ }^{\circ}{ }^{\circ} 106$, p. 75 . Crítico respecto de la figura del abuso del Derecho como correctivo del efecto de exclusión del injusto de los actos administrativos inválidos pero eficaces SCHEELE, Zur Bindung des Strafrichters, cit. nota n o 99, pp. 138 y ss. 
De acuerdo con la solución basada en la accesoriedad limitada al acto administrativo, el otorgamiento de un registro sanitario inválido, pero dotado de eficacia jurídica, podría excluir la antijuricidad de la conducta típica de homicidio o lesiones culposos realizada por el titular del registro, salvo en aquellos casos en que este hubiera actuado con abuso del Derecho.

\subsection{Crítica a los modelos de solución dominantes}

Ninguno de los modelos anteriores ofrece respuestas satisfactorias al problema de los efectos en el injusto de autorizaciones administrativas inválidas pero eficaces. Conforme al modelo de la accesoriedad al Derecho administrativo, dicha clase de autorizaciones no permite excluir el injusto objetivo del hecho. Ello supone afirmar, necesariamente, que el titular del permiso ha quebrantado un deber de conducta. Sin embargo, y como veremos con más detalle en el apartado siguiente (infra 3.5.), en aquellos casos en que el titular de un permiso ha entregado previamente a la Administración toda la información necesaria para que esta evalúe adecuadamente el riesgo, y que luego actúa sin advertir los vicios jurídicos que afectan al acto, no infringe ningún deber de comportamiento. ${ }^{115}$ Por consiguiente, es incorrecto tratar al titular de la autorización como si este hubiese realizado una conducta típica y antijurídica, y (recién) eximirlo de responsabilidad por haber incurrido en un supuesto error de permisión excluyente de la culpabilidad. En los casos referidos, el titular de la autorización no actúa desconociendo el carácter injusto de su conducta, sino que, derechamente, no realiza ningún injusto de comportamiento, ya que actúa de manera correcta, considerando su situación y su rol. ${ }^{116}$

La solución basada en la accesoriedad limitada al acto tampoco ofrece una respuesta satisfactoria al problema de las autorizaciones viciadas pero eficaces. Es cierto que la mayoría de los actos administrativos que adolecen de vicios de nulidad no dejan de producir efectos jurídicos, tal como puede inferirse del inc. $8^{\circ}$ del art. $3^{\circ}$ de la Ley $\mathrm{N}^{\circ}$ 19.880; sin embargo, la cuestión relevante es esclarecer en qué consisten, concretamente, tales efectos. La eficacia de un acto administrativo inválido, de contenido favorable significa (únicamente) que el ciudadano puede confiar en que el acto desplegará todos sus efectos de ampliación de la esfera de la libertad mientras no sea invalidado o anulado. ${ }^{117} \mathrm{La}$ eficacia no trae como consecuencia que una autorización administrativa, que adolece de vicios de nulidad, excluya la antijuricidad de un hecho punible, porque una autorización que se aparta de las exigencias que impone el Derecho administrativo material no puede crear permisos para realizar conductas típicas, valorándolas, así, como acciones compatibles con el ordenamiento jurídico. ${ }^{118}$ Otra importante crítica que se puede formular a la teoría de la accesoriedad limitada al acto consiste en que no logra explicar cómo, en los supuestos de abuso del Derecho, un acto administrativo puede dejar de tener efectos

\footnotetext{
${ }^{115}$ Cfr. FRISCH, Verwaltungsakzessorietät, cit. nota $\mathrm{n}^{\circ} 38$, pp. 60 y ss.; de acuerdo con él MAYER, Strafrechtliche Produktverantwortung, cit. nota n ${ }^{\circ}$ 7, p. 561; SCHWARZ, "Zum richtigen Verständnis", cit. nota ${ }^{\circ}$ 47, p. 326. En un sentido similar OSTENDORF, Heribert, "Die strafrechtliche Rechtmäßigkeit rechtswidrigen hoheitlichen Handelns", JZ (1981), pp. 165-175, p. 174, quien considera que el comportamiento del titular de la autorización administrativa que actúa "de buena fe" es socialmente adecuado, por lo que se debe negar la tipicidad.

${ }^{116}$ Así FRISCH, Verwaltungsakzessorietät, cit. nota n ${ }^{\circ}$ 38, p. 72; de acuerdo con él MAYER, Strafrechtliche Produktverantwortung, cit. nota $\mathrm{n}^{\circ} 7$, p. 555.

${ }^{117}$ En este sentido SCHMITZ, Roland, Verwaltungshandeln und Strafrecht, Heidelberg: C.F. Müller, 1992, p. 40. El fundamento de la eficacia de los actos administrativos que adolecen de vicios o ilegalidades se halla en el valor de la seguridad jurídica, y en la protección de la confianza legítima en la actuación ajustada a Derecho en la Administración (KORTE, Stefan, "§ 48 Wirksamkeit und Rechtmäßigkeit von Verwaltungsakten", en: Wolff/Bachof/Stober/Kluth Verwaltungsrecht, t. I, 13 ${ }^{\text {a }}$ edición, München: C.H. Beck, 2017, número marginal 38). Solo si el particular puede confiar en la validez del acto administrativo, estará en condiciones de ejercer plenamente su libertad, reconocida por la decisión estatal. Sobre la confianza legítima en el actuar de la Administración CORDERO, Luis, Lecciones de Derecho administrativo, $2^{\mathrm{a}}$ edición, Santiago: Thomson Reuters, 2015, p. 307).

${ }^{118}$ Cfr. FRISCH, Verwaltungsakzessorietät, cit. nota n ${ }^{\circ} 38$, pp. 83 y s. (la cursiva es nuestra).
} 
CONTRERAS, Lautaro, "La autorización administrativa como pauta para determinar la conducta típica en los delitos culposos de homicidio y lesiones: una cuestión de orden primario de comportamiento ejemplificada a través del otorgamiento de registros sanitarios".

jurídicos (y no excluir, entonces, la antijuricidad del hecho) por la simple conducta previa del titular del permiso. ${ }^{119}$

Considerando las importantes objeciones a las que se ven expuestos los planteamientos tradicionales sobre los efectos en el injusto de autorizaciones administrativas inválidas, pero eficaces, es necesario exponer una solución alternativa al problema.

\subsection{La delimitación de ámbitos de responsabilidad entre el Instituto de Salud Pública y el titular del registro sanitario como aspecto decisivo para determinar los efectos del otorgamiento de un registro inválido}

Lo decisivo para abordar correctamente el problema relativo a los efectos penales de las autorizaciones administrativas inválidas, pero eficaces, no consiste en la idea de que estas sean objetivamente contrarias a las exigencias del Derecho administrativo material; tampoco son relevantes los efectos jurídicos que puedan tener los actos de la Administración viciados, que alcanzarían (supuestamente) el plano de la antijuricidad penal. Antes bien, lo decisivo para resolver este problema es la consideración de los deberes jurídicos que los funcionarios de la Administración, por una parte, y los solicitantes de la autorización, por otra, han de cumplir, en el marco de un sistema de control estatal previo a la realización de una actividad peligrosa, y los consiguientes ámbitos de responsabilidad diferenciados que surgen de tales deberes. ${ }^{120}$

En efecto, en la mayoría de las situaciones cotidianas en que la conducta de un sujeto puede crear riesgos para la vida y salud de los demás, se espera que sea él mismo quien adecúe en todo momento su comportamiento a la pretensión de reconocimiento que esos bienes jurídicos reclaman. ${ }^{121}$ Así, el padre que tiene bajo su cuidado a un niño de corta edad, el conductor de un autobús que se desplaza por la ciudad, el médico encargado de ejecutar una cirugía cardíaca, etc., tienen la obligación de orientar permanentemente por sí mismos (de manera autorresponsable) su comportamiento. En estos casos, recae en el propio ámbito de responsabilidad del padre, del conductor o del médico, la determinación de cuáles son las conductas toleradas o prohibidas frente a la vida y salud de los demás, para lo cual ha de prever en todo momento los posibles cursos causales lesivos y ajustar su comportamiento a estos.

La situación es enteramente distinta en materia de distribución de productos farmacéuticos; en este ámbito, la fijación de cuál es la distribución permitida y cuál es la prohibida recae, según la normativa extrapenal, en el ámbito de responsabilidad exclusivo de la Administración. ${ }^{122} \mathrm{La}$ autorregulación responsable del comportamiento, que rige en la inmensa mayoría de las situaciones cotidianas, es reemplazada en este caso por un sistema de orientación de conductas "desde afuera". ${ }^{123}$ La intervención del ISP para autorizar o no la distribución de un determinado medicamento se justifica en razón de la complejidad de los riesgos farmacológicos ( icon la consiguiente dificultad en determinar cuándo estos han de ser asumidos socialmente!), y también de la necesidad de concretar para la situación particular pautas y criterios generales contenidos en la respectiva reglamentación extrapenal. ${ }^{24}$ De conformidad con esta normativa, el ISP asume el rol de instancia

\footnotetext{
${ }^{119}$ La crítica se puede encontrar en FRISCH, Verwaltungsakzessorietät, cit. nota n ${ }^{\circ} 38$, p. 71.

${ }^{120}$ Cfr. MAYER, Strafrechtliche Produktverantwortung, cit. nota n ${ }^{\circ} 7$, pp. 561 y 562.

${ }^{121}$ Así FRISCH, Verwaltungsakzessorietät, cit. nota ${ }^{\circ}$ 38, p. 60.

${ }^{122}$ Efectivamente, de acuerdo con el art. 59 letra b), numeral 2, del Decreto con Fuerza de Ley $\mathrm{N}^{\circ}$ 1, de 2005, del Ministerio de Salud, que fija el texto refundido, coordinado y sistematizado del DL No 2.763 y de las leyes números 18.933 y 18.469, corresponde (exclusivamente) al Instituto de Salud Pública autorizar y registrar productos farmacéuticos.

${ }^{123}$ Cfr. MAYER, Strafrechtliche Produktverantwortung, cit. nota ${ }^{\circ} 7$, p. 561; RONZANI, Marco, Erfolg und individuelle Zurechnung im Umweltstrafrecht, Freiburg im Breisgau: Max-Planck-Institut, 1992, p. 119.

${ }^{124}$ Véase, en este sentido, FRISCH, Verwaltungsakzessorietät, cit. nota $\mathrm{n}{ }^{\circ} 38$, p. 61; MAYER, Strafrechtliche Produktverantwortung, cit. nota ${ }^{\circ} 7$, p. 561.
} 
competente para velar por los intereses de protección de los usuarios de medicamentos, adoptando una decisión sobre la distribución del producto que es vinculante desde el punto de vista jurídico. ${ }^{125} \mathrm{Si}$ el ordenamiento primario le asigna al ISP ese rol, entonces sus funcionarios están obligados a desempeñarlo correctamente. ${ }^{126}$ Esto significa que, en el proceso de análisis de los antecedentes acompañados por el solicitante de un registro sanitario, aquellos funcionarios deben ponderar de manera adecuada la relación riesgobeneficio terapéutico del fármaco, y no pueden autorizar el registro de un medicamento que, según las normas de fondo aplicables, no debe ser distribuido. ${ }^{127}$ Como la correcta ponderación de la relación riesgo-beneficio terapéutico del medicamento forma parte del ámbito de responsabilidad exclusivo de los funcionarios del ISP, el titular del registro no tiene ningún deber jurídico de revisar tal ponderación; antes bien, puede confiar en que la autorización de distribución satisface todos los requisitos a los que el Derecho subordina su validez (entre ellos, el cumplimiento de las normas de fondo aplicables), al menos mientras no existan indicios claros en un sentido contrario. ${ }^{128} \mathrm{Si}$ se pretende que el otorgamiento de un registro sanitario sirva, efectivamente, como pauta de orientación de comportamientos "desde afuera", el titular debe poder confiar en la validez de dicho acto. ${ }^{129}$

Ahora bien, la confianza en la validez del otorgamiento de un registro solo puede ser digna de protección cuando la Administración haya estado en condiciones de valorar, y enjuiciar correctamente, la dimensión de riesgo del respectivo medicamento. ${ }^{130}$ Para eso, el ISP tiene que conocer todas las características farmacéuticas, farmacológicas, toxicológicas y clínicas del producto. Como ningún órgano estatal encargado de la autorización de medicamentos tiene la capacidad de llevar a cabo investigaciones propias acerca de las características de todos y cada uno de los productos farmacéuticos, las regulaciones extrapenales en la materia establecen un sistema de "examen de documentación". ${ }^{131}$ De este modo, a través del análisis detallado de los respectivos antecedentes escritos, el ISP puede controlar la plausibilidad y corrección de los datos entregados, y contrastarlos con experiencias y estándares internacionales. ${ }^{132} \mathrm{El}$ correcto funcionamiento del sistema basado en el examen de documentación depende de que el solicitante del registro cumpla con el deber jurídico de entregar a la Administración los antecedentes escritos relativos a las propiedades del producto, los que deben ser completos y exactos. ${ }^{133} \mathrm{Si}$ el titular de un registro ha cumplido con este deber, y distribuye un producto farmacéutico respecto del cual el ISP ha realizado una incorrecta ponderación de la relación riesgo-beneficio terapéutico, que no es reconocible para el titular, entonces la conducta de este no podrá calificarse como la creación de un peligro jurídicamente desaprobado para la vida o salud. Y ello, con total independencia de que el otorgamiento del respectivo registro sanitario sea inválido, al haberse apartado de las valoraciones del Reglamento de productos farmacéuticos, y sea

\footnotetext{
${ }^{125}$ Cfr. GROßE VORHOLT, Behördliche Stellungnahmen, cit. nota no 7, p. 128.

${ }^{126}$ Cfr. GROßE VORHOLT, Behördliche Stellungnahmen, cit. nota n ${ }^{\circ}$ 7, p. 128.

${ }^{127}$ Sobre el carácter eminentemente valorativo de la ponderación riesgo-beneficio terapéutico de los productos farmacéuticos véase supra nota $\mathrm{n}^{\circ} 61$.

${ }^{128}$ Cfr. FRISCH, Verwaltungsakzessorietät, cit. nota $\mathrm{n}^{\mathrm{o}}$ 38, pp. 13 y s., 73, 117; KUHLEN, Lothar, "Strafrechtliche Produkthaftung", en: ROXIN, Claus; WIDMAIER, Gunther (Editores), 50 Jahre Bundesgerichtshof - Festgabe aus der Wissenschaft - Bd. IV Strafrecht, Strafprozessrecht, München: C.H. Beck, 2000, pp. 647-673, p. 662; MAYER, Strafrechtliche Produktverantwortung, cit. nota n ${ }^{\circ}$ 7, pp. 333 y 561; TIEDEMANN, "Körperverletzung", cit. nota n ${ }^{\circ} 7$, p. 778; WEI $\beta$, Die rechtliche Gewährleistung, cit. nota n ${ }^{\circ}$ 7, p. 506. El que la autorización administrativa para distribuir productos farmacéuticos se emita luego del transcurso de un procedimiento extremadamente formalizado, y en cual participan expertos, aumenta la confianza el ciudadano en la corrección del permiso estatal (Cfr. SACH, Genehmigung, cit. nota nº 17, p. 48). ${ }^{129}$ Cfr. FRISCH, Verwaltungsakzessorietät, cit. nota ${ }^{\circ} 38$, pp. 85 y 86.

${ }^{130}$ Véase GROßE VORHOLT, Behördliche Stellungnahmen, cit. nota ${ }^{\circ}$ 7, pp. 119 y s.; MAYER, Strafrechtliche Produktverantwortung, cit. nota $\mathrm{n}^{\circ} 7$, p. 562; cfr. además OTTO, "Die strafrechtliche Verantwortung", cit. nota $\mathrm{n}^{\circ} 74$, pp. 354 y s.

${ }^{131}$ Cfr. DI FABIO, Udo, Risikoentscheidungen im Rechtsstaat - Zum Wandel der Dogmatik im öffentlichen Recht, insbesondere am Beispiel der Arzneimittelüberwachung, Tübingen: Mohr Siebeck, 1994, pp. 185 y s.; GEORGY, Die strafrechtliche Verantwortlichkeit, cit. nota $\mathrm{n}^{\circ}$ 61, p. 127; MAYER, Strafrechtliche Produktverantwortung, cit. nota ${ }^{\circ}{ }^{\circ}$, p. 563.

${ }^{132}$ Cfr. DI FABIO, Risikoentscheidungen, cit. nota $\mathrm{n}^{\circ} 131, \mathrm{p} .186$.

${ }^{133}$ Cfr. art. 28 del Reglamento de productos farmacéuticos.
} 
indeseado desde el punto de vista de los bienes jurídicos referidos. ${ }^{134}$ En este caso, el titular del registro no ha infringido ningún deber jurídico destinado a la protección de la vida y salud, cuyo cumplimiento esté situado en su ámbito de responsabilidad; por el contrario, ha entregado al ISP la información necesaria para que este adopte una decisión correcta respecto a la relación riesgo-beneficio terapéutico. Si el titular del registro no quebrantó ningún deber jurídico destinado a la protección de la vida y salud, su conducta no será típica en el sentido de los delitos culposos de homicidio o lesiones.

A diferencia del planteamiento anterior, que niega la realización de una conducta típica en los casos de acciones autorizadas por actos administrativos inválidos, cuyos vicios de nulidad no son reconocibles por el titular del permiso, la solución de la accesoriedad limitada al acto excluye el injusto penal recién en el nivel de la antijuricidad. Sin embargo, y como ya vimos, esta solución no logra explicar cómo un acto administrativo inválido puede conferir un derecho a realizar una conducta típica. La teoría de la accesoriedad limitada al acto desconoce la importancia que tiene, en la resolución del problema de los efectos de autorizaciones inválidas en el injusto, una adecuada comprensión de los deberes jurídicos que han de cumplir los funcionarios de la Administración y los titulares de los permisos estatales. ${ }^{135}$ Por su parte, la teoría de la accesoriedad al Derecho administrativo también desatiende la relevancia de esos deberes jurídicos, al estimar que el titular de un permiso inválido, quien no reconoce su carácter defectuoso, realiza un injusto objetivo y solo puede ser eximido de responsabilidad a través de un error de permisión, en circunstancias que, en realidad, se ha comportado del todo correctamente según su rol y situación. ${ }^{136}$

La calificación del comportamiento consistente en distribuir un medicamento, respecto del cual el ISP hizo una incorrecta ponderación de la relación riesgo-beneficio terapéutico, es muy distinta si el titular del registro, de manera culposa, ha infringido su deber de entregar al Instituto datos completos y correctos sobre las propiedades del medicamento $\mathrm{o}^{137}$, incluso, ha engañado de manera consciente a los funcionarios, o los ha coaccionado, sobornado o actuado en colusión con ellos, con la finalidad de alterar la correcta ponderación riesgo-beneficio terapéutico y obtener así una autorización para distribuir el producto. En cualquiera de estos casos, el titular del registro no ha aportado aquello que está situado en su propio ámbito de responsabilidad, y que garantiza que la Administración adopte una decisión correcta frente a los bienes jurídicos vida y salud individual. Por eso, en estos casos, el titular ya no puede confiar en que el acto administrativo exprese una adecuada delimitación entre los intereses en la libertad y en la conservación de bienes. ${ }^{138} \mathrm{~A}$ causa de la influencia contraria a deber que ha ejercido en la decisión de la autoridad, rige para el titular del registro derechamente la prohibición de distribuir el producto; si la infringe, estará creando riesgos jurídicamente desaprobados en relación con los tipos penales de homicidio y lesiones corporales. ${ }^{139} \mathrm{Y}$ esto, con independencia de la presunción

\footnotetext{
${ }^{134}$ Cfr. FRISCH, Verwaltungsakzessorietät, cit. nota $\mathrm{n}^{\circ} 38$, p. 63.

${ }^{135}$ FRISCH, Verwaltungsakzessorietät, cit. nota ${ }^{\circ} 38$, p. 68.

${ }^{136}$ FRISCH, Verwaltungsakzessorietät, cit. nota $\mathrm{n}^{\mathrm{o}} 38, \mathrm{pp} .69$ y 72.

${ }^{137} \mathrm{La}$ posibilidad de que el titular de un registro haya entregado antecedentes que no correspondan a las propiedades reales de un producto farmacéutico aparece recogida en el art. 59 letra b) del Reglamento, según el cual todo registro puede ser cancelado cuando cualquiera de los datos suministrados en la respectiva solicitud haya sido acreditado como falso. La norma no distingue si el suministro de antecedentes falsos se debe a negligencia o a intención deliberada del solicitante.

${ }^{138}$ Véase FRISCH, Verwaltungsakzessorietät, cit. nota $\mathrm{n}{ }^{\circ}$ 38, pp. 73 y 74; MAYER, Strafrechtliche Produktverantwortung, cit. nota ${ }^{\circ}{ }^{\circ}$, p. 564; cfr. además SCHÜNEMANN, Bernd, "Zur Dogmatik und Kriminalpolitik des Umweltstrafrechts" en: SCHMOLLER, Kurt (Editor), Festschrift für Otto Triffterer zum 65. Geburtstag, Wien: Springer, 1996, pp. 437-456, p. 447.

${ }^{139}$ Se podría plantear la pregunta de si el titular de un registro que lo ha obtenido con engaño, coacción, soborno o colusión, crea un riesgo jurídicamente desaprobado (en el sentido de los delitos de homicidio y lesiones corporales) en aquellos casos en los cuales el registro igualmente se hubiera concedido sin esos medios indebidos. Aquí será relevante la práctica jurídicamente consolidada en el marco del principio de igualdad (cfr. FRISCH, Verwaltungsakzessorietät, cit. nota ${ }^{\circ} 38$, pp. 75 y 76). Si conforme a dicha práctica,
} 


\section{Polít. Crim. Vol. 14, № 28 (Diciembre 2019), Art. 11, pp. 411-440. \\ [http://politcrim.com/wp-content/uploads/2019/12/Vol14N28A11.pdf]}

de validez de los registros sanitarios, puesto que lo decisivo aquí no es la eficacia jurídica que puedan tener actos administrativos inválidos, sino solo un correcto entendimiento de los deberes de conducta que el titular de un registro tiene que acatar. ${ }^{140}$

\section{Los registros sanitarios obsoletos}

Finalmente, corresponde abordar el problema que se puede presentar respecto a los registros sanitarios obsoletos. Se trata de casos en los cuales, estando vigente un registro sanitario válido, ${ }^{141}$ la empresa farmacéutica toma conocimiento de cierta información relativa a los efectos secundarios del producto, que el ISP no tuvo a la vista al momento de conceder el registro. Los autores que defienden el modelo de accesoriedad al acto administrativo sostienen que las autorizaciones estatales obsoletas no dejan de ser eficaces jurídicamente y, por lo tanto, producen el efecto de excluir el injusto penal (en cualquier caso, mientras sigan vigentes). ${ }^{142}$ Pero la solución a este problema no se encuentra en la noción de eficacia de los actos administrativos, sino únicamente en el plano del orden primario de conducta. Este orden regula, precisamente, aquellos casos en los cuales la empresa toma conocimiento de cualquier información que pudiera suponer un cambio en la relación riesgo-beneficio terapéutico del producto farmacéutico, obligándola a comunicar esa circunstancia de manera inmediata al ISP. ${ }^{143} \mathrm{Si}$ se cumple con este deber y el Instituto no cancela el registro sanitario, o no ordena la retirada del producto del mercado, entonces la posterior distribución del producto no podrá verse como la creación de un riesgo jurídicamente desaprobado (en el sentido de los delitos de homicidio o lesiones). Los riesgos que puedan subsistir, pese al cumplimiento de este deber de comunicación por parte de la empresa titular del registro, formarán parte del ámbito de responsabilidad exclusivo de la Administración. ${ }^{144}$ En cambio, si se lesiona el deber de comunicar al ISP cualquier información que pudiera suponer una modificación en la relación riesgo-beneficio terapéutico del producto, podrá verse allí una conducta típicamente desaprobada. ${ }^{145}$

Ahora bien, si la empresa titular del registro sanitario toma conocimiento de información relativa al riesgo del medicamento de la cual se pueden desprender peligros concretos para la vida o salud de los consumidores, deberá, junto con comunicar los antecedentes al ISP, advertir a los consumidores del riesgo, o incluso retirar el producto del mercado. ${ }^{146}$

el registro igualmente se hubiera entregado, no podrá apreciarse una conducta desaprobada (en el sentido de los delitos de homicidio y lesiones corporales); por el contrario, si teniendo a la vista esa práctica, la autorización para distribuir nunca se hubiera concedido, sí deberá apreciarse una conducta desaprobada.

${ }^{140}$ Por eso, aunque un registro obtenido con antecedentes falsos no haya sido todavía cancelado de conformidad al art. 59 letra b) del Reglamento, y rija a su respecto la presunción de validez del inciso $8^{\circ}$ del art. $3^{\circ}$ de la Ley $\mathrm{N}^{\circ} 19.880$, la distribución de un producto farmacéutico que no debió haber sido autorizada por sobrepasar sus riesgos a sus beneficios terapéuticos, representará la creación de un riesgo no permitido jurídicamente.

${ }^{141}$ Por registro sanitario válido ha de entenderse, en este contexto, un registro otorgado luego de una ponderación correcta de la relación riesgo-beneficio terapéutico.

${ }^{142}$ En este sentido KUHLEN, Lothar, "Zum Umweltstrafrecht in der Bundesrepublik Deutschland (2. Teil)", Wirtschaft und Verwaltung (1992), pp. 215-301, p. 250; ROGALL, Klaus, Die Strafbarkeit von Amtsträgern im Umweltbereich, Berlin: Erich Schmidt, 1991, p. 186.

${ }^{143}$ Art. 11, letra c), de la Norma General Técnica $N^{\circ} 140$, sobre sistema nacional de farmacovigilancia de productos farmacéuticos de uso humano, aprobada por la resolución $\mathrm{N}^{\circ} 381$, de 20.06.2012, del Ministerio de Salud.

${ }^{144}$ Sobre la responsabilidad penal de los funcionarios de la Administración que no cancelan un registro sanitario, pese a la variación sustancial de la relación riesgo-beneficio de un producto farmacéutico GEORGY, Die strafrechtliche Verantwortlichkeit, cit. nota ${ }^{\circ} 61$, pp. 150 y ss.

${ }^{145}$ WEI $\beta$, Die rechtliche Gewährleistung, cit. nota n ${ }^{\circ} 7$, pp. 506 y s. Naturalmente, la conducta desaprobada será la de la persona o personas al interior de la empresa titular del registro, responsables de cumplir con ese deber de comunicación.

${ }^{146}$ CONTRERAS, Lautaro, Normative Kriterien zur Bestimmung der Sorgfaltspflichten des Produzenten, Berlin: Duncker \& Humblot, 2012, p. 142. 


\section{Conclusiones}

El estudio de las resoluciones del Instituto de Salud Púbica que otorgan registros sanitarios ha mostrado que las autorizaciones administrativas pueden servir para la delimitación entre peligros permitidos y desaprobados en los delitos imprudentes de homicidio y lesiones. Aquella persona que realiza una conducta autorizada por la Administración ejerce su libertad reconocida jurídicamente; los peligros que su comportamiento genere para la vida o salud no podrán considerarse como típicamente relevantes. Y ello, con independencia de que la autorización esté concebida en el marco de un sistema de control preventivo con reserva de permiso, o bien de control represivo con reserva de exención.

Para establecer cuáles son los peligros para la vida y salud específicamente tolerados por una autorización administrativa, es indispensable tener en consideración la normativa extrapenal que regula su dictación. El análisis detallado de esa normativa, que es ejecutada o concretada a través de la autorización, permite conocer qué específicos riesgos para bienes jurídicos se estiman como permitidos en interés del ejercicio de la libertad de acción.

Finalmente, este trabajo ha mostrado que la solución al problema de los efectos en el injusto de autorizaciones inválidas pero eficaces no se halla en los modelos de accesoriedad al Derecho, o al acto administrativo, sino en una adecuada comprensión de los deberes jurídicos que los funcionarios de la Administración, por una parte, y los solicitantes de la autorización, por otra, han de cumplir, en el contexto de un sistema de control estatal previo a la realización de actividades peligrosas. 


\section{Bibliografía}

ALEXANDER, Thorsten, Die strafrechtliche Verantwortlichkeit für die Wahrung der Verkehrssicherungspflichten in Unternehmen, Herbolzheim: Centaurus, 2005.

BASCUÑÁN, Antonio, "Comentario crítico a la regulación de los delitos contra el medio ambiente en el Anteproyecto de Código Penal de 2005", en Estudios Públicos 110 (otoño 2008), pp. 1-81, en: https://www.cepchile.cl/cep/site/artic/20160304/asocfile/20160304094528/ rev110_bascunan_regulacion.pdf [visitado el 18.08.2018].

BELADÍEZ, Margarita, Validez y eficacia de los actos administrativos, Madrid: Marcial Pons, 1994.

BERMÚDEZ, Jorge, Derecho administrativo general, $3^{\text {a }}$ edición, Santiago: Thomson Reuters, 2014.

BEULKE, Werner; SATZGER, Helmut, Strafrecht Allgemeiner Teil - Die Straftat und ihr Aufbau, $47^{\text {a }}$ edición, Heidelberg: C.F. Müller, 2017.

BLOY, René, "Die Straftaten gegen die Umwelt im System des Rechtsgüterschutzes", ZStW 100 (1988), pp. 485-507.

BOCANEGRA, Raúl, Lecciones sobre el acto administrativo, $4^{\mathrm{a}}$ edición, Cizur Menor: Thomson Reuters, 2012.

BRAUER, Jürgen, Die strafrechtliche Behandlung genehmigungsfähigen, aber nicht genehmigten Verhaltens, Berlin: Duncker \& Humblot, 1988.

BRÄUTIGAM-ERNST, Stephanie, Die Bedeutung von Verwaltungsvorschriften für das Strafrecht, Baden-Baden: Nomos, 2010.

BUSTOS, Juan, El delito culposo, Santiago: Editorial Jurídica de Chile, 1995.

CONTRERAS, Lautaro, Normative Kriterien zur Bestimmung der Sorgfaltspflichten des Produzenten, Berlin: Duncker \& Humblot, 2012.

CORDERO, Eduardo, "La nulidad de los actos administrativos y sus causales", en: FERRADA, Juan (Coordinador), IX Jornadas de Derecho Administrativo, Santiago: Thomson Reuters, 2013, pp. 189-207.

CORDERO, Luis, Lecciones de Derecho administrativo, $2^{\mathrm{a}}$ edición, Santiago: Thomson Reuters, 2015.

COUSO, Jaime, "Art. 10 n 10 ", en: COUSO, Jaime; HERNÁNDEZ, Héctor (Editores), Código Penal comentado, Santiago: Legal Publishing, 2011, pp. 260-266.

DE LA MATA, Norberto, Protección penal del ambiente y accesoriedad administrativa - Tratamiento penal de comportamientos perjudiciales para el ambiente amparados en una autorización administrativa ilícita, Barcelona: Cedecs, 1996.

DE LA MATA, Norberto; DE LA MATA, Ignacio, "La figura de la autorización en la lesión de bienes jurídico-penales de carácter supraindividual”, en: LÓPEZ, Jacobo; ZUGALDÍA, José (Editores), Dogmática y ley penal - Libro homenaje a Enrique Bacigalupo, vol. I, Madrid: Marcial Pons, 2004, pp. 483-504.

DI FABIO, Udo, Risikoentscheidungen im Rechtsstaat - Zum Wandel der Dogmatik im öffentlichen Recht, insbesondere am Beispiel der Arzneimittelüberwachung, Tübingen: Mohr Siebeck, 1994.

DÖLLING, Dieter, "Umweltstraftat und Verwaltungsrecht”, JZ (1985), pp. 461-469.

FELIX, Dagmar, Einheit der Rechtsordnung - Zur verfassungsrechtlichen Relevanz einer juristischen Argumentationsfigur, Tübingen: Mohr Siebeck, 1998.

FERRAJOLI, Luigi, Derecho y razón - Teoría del garantismo penal, Madrid: Trotta, 1995.

FLUCK, Jürgen, "Die Legalisierungswirkung von Genehmigungen als ein Zentralproblem öffentlich-rechtlicher Haftung für Altlasten", Verwaltungsarchiv tomo 79 (1988), pp. 406444.

FORTUN, Steffen, Die behördliche Genehmigung im strafrechtlichen Deliktsaufbau, Berlin: Duncker \& Humblot, 1998.

FREUND, Georg, "§ 5 AMG”, en: JOECKS, Wolfgang; MIEBACH, Klaus (Editores), Münchener Kommentar zum Strafgesetzbuch, t. 6, 33 edición, München: C.H. Beck, 2017, número marginal 22, en: https://beck-online.beck.de [visitado el 20.08.2018].

FRISCH, Wolfgang, "Ermessen, unbestimmter Begriff und Beurteilungsspielraum im Strafrecht", NJW (1973), pp. 1345-1349.

FRISCH, Wolfgang, Tatbestandsmäßiges Verhalten und Zurechnung des Erfolgs, Heidelberg: C.F. Müller, 1988.

FRISCH, Wolfgang, Verwaltungsakzessorietät und Tatbestandsverständnis im Umweltstrafrecht, Heidelberg: C.F. Müller, 1993.

GARCÍA DE ENTERRÍA, Eduardo; FERNÁNDEZ, Tomás-Ramón, Curso de Derecho Administrativo, t. I, $17^{\mathrm{a}}$ edición, Cizur Menor: Thomson Reuters, 2015. 
CONTRERAS, Lautaro, "La autorización administrativa como pauta para determinar la conducta típica en los delitos culposos de homicidio y lesiones: una cuestión de orden primario de comportamiento ejemplificada a través del otorgamiento de registros sanitarios".

GEORGY, Philipp, Die strafrechtliche Verantwortlichkeit von Amtsträgern für Arzneimittelrisiken Am Beispiel öffentlich-rechtlicher Ethik-Kommissionen und des Bundesinstituts für Arzneimittel und Medizinprodukte, Berlin: Duncker \& Humblot, 2011.

GEULEN, Reiner, "Grundlegende Neuregelung des Umweltstrafrechts", ZRP (1988), pp. 323-327.

GROßE VORHOLT, André, Behördliche Stellungnahmen in der strafrechtlichen Produkthaftung, Baden-Baden: Nomos, 1997.

HEINE, Günter, Die strafrechtliche Verantwortlichkeit von Unternehmen, Baden-Baden: Nomos, 1995.

HEGHMANNS, Michael, Grundzüge einer Dogmatik der Straftatbestände zum Schutz von Verwaltungsrecht oder Verwaltungshandeln, Berlin: Duncker \& Humblot, 2000.

HERMES, Georg, "Die Wirkung behördlicher Genehmigungen: Privates Risiko oder staatliche (Mit-)Verantwortung bei veränderter Sachlage?", en: BECKER-SCHWARZE, Kathrin et al (Editores), Wandel der Handlungsformen im öffentlichen Recht / 31. Tagung der Wissenschaftlichen Mitarbeiterinnen und Mitarbeiter der Fachrichtung "Öffentliches Recht", Bremen 1991, Stuttgart: Boorberg, 1991, pp. 187-211.

HORN, Eckhard, "Erlaubtes Risiko und Risikoerlaubnis - Zur Funktion des Prüfstellensystems nach $\S 155$ AE”, en: STRATENWERTH, Günter (Editor), Festschrift für Hans Welzel zum 70. Geburtstag am 25. März 1974, Berlin: Walter De Gruyter, 1974, pp. 719-737.

HORN, Eckhard, "Strafbares Fehlverhalten von Genehmigungs- und Aufsichtsbehörden?", NJW (1981), pp. 1-11.

HÜBENETT, Carolin, Rechtswidrige behördliche Genehmigung als Rechtfertigungsgrund - ein gelöstes strafrechtliches Problem? - Dargestellt an § 324 StGB (Gewässerverunreinigung), Bonn: sin editorial, 1986.

HUNDT, Thomas, Die Wirkungsweise der öffentlich-rechtlichen Genehmigungen im Strafrecht, Berlin: Verlag für Wissenschaft und Forschung, 1994.

HÜWELS, Hermann, Fehlerhafter Gesetzesvollzug und strafrechtliche Zurechnung, Berlin: Duncker \& Humblot, 1986.

JAKOBS, Günther, Strafrecht Allgemeiner Teil, 2a edición, Berlin: Walter de Gruyter, 1991.

JARA, Jaime, La nulidad de Derecho público ante la doctrina y la jurisprudencia, Santiago: Libromar, 2004.

KAUFMANN, Armin, "Rechtspflichtbegründung und Tatbestandseinschränkung", en: KOHLMAN, Günter (Editor), Festschrift für Ulrich Klug zum 70. Geburtstag, t. 2, Köln: Deubner, 1983, pp. 277-292.

KLUTH, Winfried, "§31 Gesetzesgebundenheit und Verwaltungsspielräume", Wolff/Bachof/Stober/Kluth Verwaltungsrecht I, $13^{\mathrm{a}}$ edición, München: C.H. Beck, 2017, pp. 337-362

KORTE, Stefan, "§46 Arten der Verwaltungsakte", en: Wolff/Bachof/Stober/Kluth Verwaltungsrecht, t. I, $13^{\mathrm{a}}$ edición, München: C.H. Beck, 2017, pp. 545-560.

KORTE, Stefan, "§ 47 Nebenbestimmungen zu Verwaltungsakten”, en: Wolff/Bachof/Stober/Kluth Verwaltungsrecht, t. I, $13^{\mathrm{a}}$ edición, München: C.H. Beck, 2017, pp. 560-577.

KORTE, Stefan, "§ 48 Wirksamkeit und Rechtmäßigkeit von Verwaltungsakten", en: Wolff/Bachof/Stober/Kluth Verwaltungsrecht, t. I, 13ª edición, München: C.H. Beck, 2017, pp. 577-601.

KUHLEN, Lothar, "Zum Umweltstrafrecht in der Bundesrepublik Deutschland (2. Teil)", Wirtschaft und Verwaltung (1992), pp. 215-301.

KUHLEN, Lothar, "Strafrechtliche Produkthaftung", en: ROXIN, Claus; WIDMAIER, Gunther (Editores), 50 Jahre Bundesgerichtshof - Festgabe aus der Wissenschaft - Bd. IV Strafrecht, Strafprozessrecht, München: C.H. Beck, 2000, pp. 647-673.

KÜHL, Kristian, Strafrecht Allgemeiner Teil, $8^{a}$ edición, München: Vahlen, 2017.

KÜHL, Kristian; HEGER, Martin, Strafgesetzbuch Kommentar, 29a edición, München: C.H. Beck, 2018.

LAGUNA, José, La autorización administrativa, Cizur Menor: Thomson Reuters, 2006.

LENCKNER, Theodor, "Behördliche Genehmigungen und der Gedanke der Rechtsmißbrauchs im Strafrecht", en: VON GAMM, Otto-Friedrich et al (Editores), Strafrecht, Unternehmensrecht, Anwaltsrecht - Festschrift für Gerd Pfeiffer zum Abschied aus dem Amt als Präsident des Bundesgerichtshofes, Köln: Carl Heymann, 1988, pp. 27-43.

MADARIAGA, Mónica, Seguridad jurídica y administración pública en el siglo XXI, $2^{a}$ edición, Santiago: Editorial jurídica de Chile, 1993. 
MARÍN, Urbano, "Vigencia actual de la invalidación de los actos administrativos", Revista de Derecho (Consejo de Defensa del Estado), Año 1 - n ${ }^{\circ} 2$ (diciembre 2000), pp. 45-60.

MATUS, Jean Pierre; RAMÍREZ, Cecilia, Lecciones de Derecho penal chileno - Fundamentos y límites constitucionales del Derecho penal positivo, $3^{\mathrm{a}}$ edición, Santiago: Legal Publishing Chile, 2015.

MAURER, Hartmut; WALDHOFF, Christian, Allgemeines Verwaltungsrecht, 19 a edición, München: C.H. Beck, 2017.

MAYER, Laura; VERA, Jaime, “Autorización de plantas de revisión técnica e imputación objetiva en delitos culposos del tráfico vehicular", Revista de Derecho (Valdivia) vol. XXXI, N. 1 (2018), pp. 327-345.

MAYER, Michael, Strafrechtliche Produktverantwortung bei Arzneimittelschäden - Ein Beitrag zur Abgrenzung der Verantwortungsbereiche im Arzneiwesen aus strafrechtlicher Sicht, Berlin: Springer, 2008.

MAYER, Michael, "Die Arzneimittelzulassung als Strafbarkeitshindernis”, MedR (2008), pp. 595598.

MIKUS, Rudolf, Die Verhaltensnorm des fahrlässigen Erfolgsdelikts, Berlin: Duncker \& Humblot, 2002.

MOHRBOTTER, Kurt, “Bindung des Strafrichters an das Handeln der Verwaltung?” JZ (1971), pp. 213-217.

MURMANN, Uwe, Grundkurs Strafrecht, $4^{\text {a }}$ edición, München: C.H. Beck, 2017.

NIERING, Christoph, Der strafrechtliche Schutz der Gewässer, Frankfurt am Main: Peter Lang, 1993.

OSTENDORF, Heribert, "Die strafrechtliche Rechtmäßigkeit rechtswidrigen hoheitlichen Handelns", JZ (1981), pp. 165-175.

OTTO, Harro, "Die strafrechtliche Verantwortung für die Verletzung von Sicherungspflichten in Unternehmen", en: HOYER, Andreas et al (Editores), Festschrift für Friedrich-Christian Schroeder zum 70. Geburtstag, Heidelberg: C.F. Müller, 2006, pp. 339-356.

PAEFFGEN, Hans-Ullrich; ZABEL, Benno, "Vorbemerkungen zu $\S 32$ ff", en: KINDHÄUSER, Urs; NEUMANN, Ulfrid; PAEFFGEN, Hans-Ullrich (Editores), Nomos Kommentar Strafgesetzbuch, $t$. 1, $5^{\text {a }}$ edición, Baden-Baden: Nomos, 2017, pp. 1350-1603.

PAPIER, Hans Jürgen, "Zur Disharmonie zwischen verwaltungs- und strafrechtlichen Bewertungsmaßstäben im Gewässerstrafrecht”, $N u R$ (1986), pp. 1-8.

RADEMACHER, Martin, Die Strafbarkeit wegen Verunreinigung eines Gewässers (\$ 324 StGB), Frankfurt am Main: Peter Lang, 1989.

RANSIEK, Andreas, “§ 324”, en: KINDHÄUSER, Urs; NEUMANN, Ulfrid; PAEFFGEN, HansUllrich (Editores), Nomos Kommentar Strafgesetzbuch, t. 3, 5 a edición, Baden-Baden: Nomos, 2017, pp. 1987-2012.

RANSIEK, Andreas, “§ 330a”, en: KINDHÄUSER, Urs; NEUMANN, Ulfrid; PAEFFGEN, HansUllrich (Editores), Nomos Kommentar Strafgesetzbuch, t. 3, $5^{\text {a }}$ edición, Baden-Baden: Nomos, 2017, pp. 2079-2081.

RÄPPLE, Thilo, Das Verbot bedenklicher Arzneimittel - Eine Kommentierung zu 5 AMG, BadenBaden: Nomos, 1991.

ROGALL, Klaus, Die Strafbarkeit von Amtsträgern im Umweltbereich, Berlin: Erich Schmidt, 1991.

ROGALL, Klaus, "Die Verwaltungsakzessorietät des Umweltsstrafrechts - Alte Streitfragen, neues Recht", GA (1995), pp. 299-319.

RÖNNAU, Thomas, "Vorbemerkungen zu den $\S \S 32$ ", en: LAUFHÜTTE, Heinrich Wilhelm et al (Editores), Strafgesetzbuch Leipziger Kommentar Großkommentar, t. 2, 12 ${ }^{\mathrm{a}}$ edición, Berlin: Walter de Gruyter, 2006, pp. 1-353.

RONZANI, Marco, Erfolg und individuelle Zurechnung im Umweltstrafrecht, Freiburg im Breisgau: Max-Planck-Institut, 1992.

ROXIN, Claus, Strafrecht Allgemeiner Teil, t. I, $4^{\mathrm{a}}$ edición, München: C.H. Beck, 2006.

RUDOLPHI, Hans-Joachim, "Primat des Strafrechts im Umweltschutz? - 1. Teil -", NStZ (1984), pp. 193-199.

RUDOLPHI, Hans-Joachim, "Strafrechtliche Verantwortlichkeit der Bediensteten von Betrieben für Gewässerverunreinigungen und ihre Begrenzung durch den Einleitungsbescheid", en: KÜPER, Winfried (Editor), Festschrift für Karl Lackner zum 70. Geburtstag, Berlin: Walter de Gruyter, 1987, pp. 863-887.

SACH, Karsten, Genehmigung als Schutzschild?: die Rechtsstellung des Inhabers einer immissionsschutzrechtlichen Genehmigung, Berlin: Duncker \& Humblot, 1994.

SALIGER, Frank, Umweltstrafrecht, München: Vahlen, 2012. 
CONTRERAS, Lautaro, "La autorización administrativa como pauta para determinar la conducta típica en los delitos culposos de homicidio y lesiones: una cuestión de orden primario de comportamiento ejemplificada a través del otorgamiento de registros sanitarios".

SALIGER, Frank, "Vorbemerkung zu den $\S 324$ ff.”, en: SATZGER, Helmut; SCHLUCKEBIER, Wilhelm (Editores), Strafgesetzbuch Kommentar, $3^{\text {a }}$ edición, Köln: Carl Heymann, 2016, pp. 2211-2239.

SALIGER, Frank, "§ 330a", en: SATZGER, Helmut; SCHLUCKEBIER, Wilhelm (Editores), Strafgesetzbuch Kommentar, $3^{a}$ edición, Köln: Carl Heymann, 2016, pp. 2319-2322.

SCHALL, Hero, "Umweltschutz durch Strafrecht: Anspruch und Wirklichkeit", NJW (1990), pp. 1263-1273.

SCHALL, Hero, "Zur Reichweite der verwaltungsbehördlichen Erlaubnis im Umweltstrafrecht", en: SCHÜNEMANN, Bernd et al (Editores), Festschrift für Claus Roxin, Berlin: Walter De Gruyter, 2001, pp. 927-944.

SCHEELE, Rolf, Zur Bindung des Strafrichters an fehlerhafte behördliche Genehmigungen im Umweltstrafrecht, Berlin: Duncker \& Humblot, 1993.

SCHLEHOFER, Horst, "Vorbemerkung zu § 32", en: JOECKS, Wolfgang; MIEBACH, Klaus (Editores), Münchener Kommentar zum Strafgesetzbuch, t. 1, $3^{\mathrm{a}}$ edición, München: C.H. Beck, 2017, en: https://beck-online.beck.de [visitado el 20.08.2018].

SCHMITZ, Roland, Verwaltungshandeln und Strafrecht, Heidelberg: C.F. Müller, 1992.

SCHRÖDER, Christian, "2. Kapitel Straf- und Bußgeldtatbestände im BörsG und WpHG", en: ACHENBACH, Hans et al (Editores), Handbuch Wirtschaftsstrafrecht, $4^{\mathrm{a}}$ edición, Heidelberg: Müller, 2015, pp. 1286-1366.

SCHÜNEMANN, Bernd, "Zur Dogmatik und Kriminalpolitik des Umweltstrafrechts" en: SCHMOLLER, Kurt (Editor), Festschrift für Otto Triffterer zum 65. Geburtstag, Wien: Springer, 1996, pp. 437-456.

SCHWARZ, Andreas, "Zum richtigen Verständnis der Verwaltungsakzessorietät des Umweltstrafrechts", GA (1993), pp. 318-328.

SOTO, Eduardo, "La nulidad de derecho público en el derecho chileno", Revista de Derecho Público Universidad de Chile, $\mathrm{n}^{\circ}$ 47-48 (1990), pp. 11-25.

SOTO, Eduardo, "La nulidad de derecho público referida a los actos de la Administración", Revista de Derecho, Universidad Católica de Valparaíso, XIV (1991-1992), pp. 417-431.

SOTO, Eduardo, "La nulidad de derecho público: su actualidad", Revista de Derecho, Universidad Católica de Valparaíso, XVIII (1997), pp. 347-355.

STERNBERG-LIEBEN, Detlev, "Vorbemerkungen zu den $\S \S 32$ ff.", en: Schönke/Schröder Strafgesetzbuch Kommentar, 30a edición, München: C.H. Beck, 2018, en: https://beckonline.beck.de [visitado el 23.01.2019].

TIEDEMANN, Klaus, "Körperverletzung und strafrechtliche Produktverantwortung - Bemerkungen zum Fall Degussa", en: WEIGEND, Thomas; KÜPPER, Georg (Editores.), Festschrift für Hans Joachim Hirsch zum 70. Geburtstag am 11. April 1999, Berlin: Walter de Gruyter, 1999, pp. 765-778.

TIEDEMANN, Klaus; ENGELHART, Marc, Wirtschaftsstrafrecht, $5^{\text {a }}$ edición, München: Vahlen, 2017.

VELASCO, Francisco, Las cláusulas accesorias del acto administrativo, Madrid: sin editorial, 1994, en: https://repositorio.uam.es/xmlui/handle/10486/4881 [visitado el 10.08.2018].

VOGEL, Joachim, "§ 15 Vorsätzliches und fahrlässiges Handeln”, en: LAUFHÜTTE, Heinrich et al (Editores), Strafgesetzbuch Leipziger Kommentar Großkommentar, t. 2, 12 ${ }^{\mathrm{a}}$ edición, Berlin: Walter de Gruyter, 2007, pp. 991-1115.

WEI $\beta$, Holger, Die rechtliche Gewährleistung der Produktsicherheit, Baden-Baden: Nomos, 2008.

WINKELBAUER, Wolfgang, Zur Verwaltungsakzessorietät des Umweltstrafrechts, Berlin: Duncker \& Humblot, 1985. 